\title{
Using Computational Fluid Dynamics and Experiments to Design Sweeping Jets for High Reynolds Number Cruise Configurations
}

\author{
Gregory S. Jones ${ }^{1}$, William E. Milholen, $\mathrm{II}^{2}$, Jared S. Fell ${ }^{3}$, Sandy R. Webb ${ }^{3}$, C. Mark Cagle ${ }^{3}$ \\ NASA Langley Research Center, Hampton, VA, 23681
}

The application of a sweeping jet actuator to a circulation control system was initiated by a risk reduction series of experiments to optimize the authority of a single sweeping jet actuator. The sweeping jet design was integrated into the existing Fundamental Aerodynamic Subsonic TransonicModular Active Control (FAST-MAC) model by replacing the steady blowing system with an array of thirty-nine sweeping jet cartridges. A constant slot height to wing chord ratio was similar to the steady blowing configuration resulting in each actuator having a unique in size for the sweeping jet configuration. While this paper will describe the scaling and optimization of the actuators for future high Reynolds number applications, the major focus of this effort was to target the transonic flight regime by increasing the amplitude authority of the actuator. This was accomplished by modifying the diffuser of the sweeping jet actuator, and this paper highlights twelve different diffuser designs. The experimental portion of this work was completed in the NASA Langley National Transonic Facility.

\begin{tabular}{|c|c|c|c|}
\hline \multirow[b]{2}{*}{$\mathrm{A}_{\mathrm{T}}$} & \multicolumn{3}{|c|}{ Nomenclature } \\
\hline & $=$ throat area $\left(\mathrm{in}^{2}\right)$ & $\mathrm{x}$ & $=$ distance from throat (in) \\
\hline$A_{0}$ & $=$ area of a single orifice $\left(\mathrm{in}^{2}\right)$ & $\mathrm{X}$ & $=$ distance from diffuser exit (in) \\
\hline $\mathrm{b}$ & $=$ wing $\operatorname{span}($ in $)$ & $\mathrm{Z}_{\mathrm{REF}}$ & $=$ reference width of diffuser exit (in) \\
\hline $\mathrm{C}_{\mu}$ & $=$ momentum coefficient $\left(\dot{m} U_{J E T} / q_{\infty} S\right)$ & & \\
\hline$C_{p}$ & $=$ pressure coefficient & Acrony & yms \\
\hline $\mathrm{c}$ & $=$ chord (in) & $\mathrm{AFC}$ & $\overline{=}$ active flow control \\
\hline $\mathrm{f}^{+}$ & $=$nondimensional frequency & CFD & $=$Computational Fluid Dynamics \\
\hline$f$ & $=$ frequency $(\mathrm{Hz})$ & EDM & $=$ electrical discharge machining \\
\hline $\mathrm{g}$ & $=$ acceleration due to gravity, $32.17 \mathrm{ft} / \mathrm{sec}^{2}$ & NTF & $=$ National Transonic Facility \\
\hline $\mathrm{h}$ & $=$ actuator throat height (in) & SLA & $=$ stereolithography \\
\hline$\dot{m}$ & $=$ massflow $(\mathrm{lbm} / \mathrm{sec})$ & SMSS & $=$ Sidewall Model Support System \\
\hline $\mathrm{M}_{\infty}$ & $=$ freestream Mach number & & \\
\hline NPR & $=$ nozzle pressure ratio $\left(\mathrm{P}_{\mathrm{O}(\mathrm{J})} / \mathrm{P}\right)$ & Greek & Symbols \\
\hline $\mathrm{P}_{\mathrm{O}(\mathrm{J})}$ & $=$ jet total pressure $(\mathrm{psi})$ & $\alpha$ & $=$ angle of attack (degrees) \\
\hline $\mathrm{q}_{\infty}$ & $=$ freestream dynamic pressure $(\mathrm{psf})$ & $\theta$ & $=$ jet sweep angle (degrees) \\
\hline $\mathrm{Re}_{\mathrm{C}}$ & $=$ chord Reynolds number & $\lambda$ & $=$ wave length $(\mathrm{ft})$ \\
\hline S & $=$ wing planform area $\left(\mathrm{ft}^{2}\right)$ & $\rho$ & $=$ density $\left(\mathrm{lb} / \mathrm{ft}^{3}\right)$ \\
\hline SPL & $=$ sound pressure level (decibels) & & \\
\hline $\mathrm{T}_{\mathrm{O}}$ & $=$ wind tunnel total temperature $\left({ }^{\circ} \mathrm{F}\right)$ & $\underline{\text { Subscri }}$ & ipts \\
\hline $\mathrm{T}_{\mathrm{O}(\mathrm{JET})}$ & $=$ jet total temperature $\left({ }^{\circ} \mathrm{F}\right)$ & Exit & $=$ condition at the diffuser exit \\
\hline $\mathrm{U}_{\mathrm{JET}}$ & $=$ actuator throat velocity $(\mathrm{ft} / \mathrm{sec})$ & Jet & $=$ condition at the throat \\
\hline $\mathrm{U}_{\mathrm{EXIT}}$ & $=$ diffuser exit velocity $(\mathrm{ft} / \mathrm{sec})$ & TE & $=$ trailing edge of flap \\
\hline & & $\infty$ & $=$ stagnation quantity \\
\hline & & $\mathrm{rms}$ & $=$ root mean square \\
\hline
\end{tabular}

\footnotetext{
${ }^{1}$ Research Aerospace Engineer, Configuration Aerodynamics Branch, Mail Stop 267, AIAA Senior Member.

${ }^{2}$ Research Aerospace Engineer, Configuration Aerodynamics Branch, Mail Stop 499, AIAA Senior Member.

${ }^{3}$ Design Engineer, Aeronautics Systems Engineering Branch, Mail Stop 238.
} 


\section{Introduction}

$\mathrm{R}$ ecent Active Flow Control (AFC) experiments in the NASA Langley National Transonic Facility (NTF) have demonstrated the benefits of circulation control for high-lift and cruise configurations on the Fundamental Aerodynamic Subsonic Transonic-Modular Active Control (FAST-MAC) model ${ }^{1,2,3}$. These experiments have focused only on steady blowing conditions. Historically, these configurations are related to circulation control efforts ${ }^{4}$ that relate the lift performance of a wing to the momentum coefficient of the jet. In general, circulation control benefits for high-lift configurations occur in one of two regimes that include separation control and supercirculation. The transition of separation control and super-circulation is where the jet reattaches the separated flow to the trailing edge of the upper surface of the flap as shown in Figure 1. Reference 5 discusses the separation and super-circulation regimes for the FAST-MAC model and shows the separation control benefits for the $60^{\circ}$ flap to occur at momentum coefficients between zero and 0.04. Reference 1 discusses the cruise benefits (Mach $=0.85$, $\operatorname{Re}_{\mathrm{c}}=30 \times 10^{6}$ ) for the $0^{\circ}$ flap. The cruise benefits were limited to momentum coefficients between 0.005 and 0.007 . Blowing too little or too much proved to increase cruise drag due to a detrimental influence of the jet on local shocks and boundary layer separation on the flap.

A continuation of the FAST-MAC effort is focused on characterizing the wing performance for an unsteady sweeping jet configuration. The goal of the sweeping jet effort is to reduce the mass flow requirements of the blowing system in the separation control regime while achieving lift and drag benefits for both the high-lift and cruise configurations at high Reynolds number conditions. To achieve this goal, the sweeping jet must have the authority to control boundary layer separation on both the high-lift and cruise flap configurations. This paper emphasizes the design methodology and rapid prototyping necessary to satisfy the cruise requirements and the modifications to the sweeping jet diffuser needed to achieve and sustain supersonic jet exit velocities. The primary focus of the paper will be on the effort to increase the sweeping jet magnitude authority using a bench-top setup for an individual sweeping jet.

Fluidic oscillators have been around since the early $1950 \mathrm{~s}^{6,7}$. Modern concepts that are employed in fluidic devices were first invented in 1959 by the Diamond Ordnance Fuze Laboratory. These early devices focused on simple configurations that utilized liquids as a working fluid (e.g., windshield washers, shower heads, etc.). During the past three decades, active flow control has become increasingly popular, and this includes boundary layer separation control using fluidic oscillators. ${ }^{8,9,10}$ The sweeping jet actuators described in this paper are fluidic oscillators with no moving parts. They emit a continuous, but spatially oscillating jet when connected to a steady air source. The oscillations are also self-induced and self-sustaining. Figure 2 identifies the fundamental concepts of the sweeping jet design. When pressurized, the flow enters the actuator's settling chamber through an inlet that is larger than the throat at the exit diffuser. Flow then attaches to one side of the settling chamber before entering the minimum area (throat) at an angle that will propagate through only one side of the exit diffuser. As the flow passes through the settling chamber, a small portion of the main flow is guided into the feedback channel on the same side. This small amount of flow propagates through the feedback leg to the inlet region of the settling chamber. It then interacts with the inlet flow causing the jet to attach to the opposite side of the settling chamber. As this instability moves through the settling chamber, the flow begins to vector the throat flow to the opposite side of the diffuser thereby causing a sweeping motion at the actuator exit. This process is self-sustaining at very stable frequencies, and these frequencies are dependent on the propagation of the fluid through the feedback legs, as well as the time of flight through the settling chamber, both of which are dependent on actuator scale.

Recent wind tunnel ${ }^{11,12,13}$ and flight experiments ${ }^{14}$ have demonstrated that the sweeping jet authority required to control boundary layer separation was adequate for the low-speed regime ${ }^{15,16,17}$. These advances emphasize actuator application to low-speed high-lift configurations where sweep angle authority is the driving factor ${ }^{18}$ and is used to establish the spacing of the actuators along the span. While the emphasis of the cruise configuration will focus on drag improvements, it is believed that enhancements to both jet magnitude and sweep angle authority will be required due to the higher local freestream velocities.

\section{Background}

Actuator sizing is based on the application of sweeping jet technology to the existing FAST-MAC model shown in Figure 3. A tangential blowing slot is located at the $85 \%$ chord location on the upper surface, and the jet was directed over a $15 \%$-chord simple hinged flap for both the cruise and high-lift modes. The semi-span wing is based on a supercritical geometry that was designed to become an NTF standard for evaluating performance characteristics of integrated active flow control and propulsion systems. The wing has an aspect ratio of 5.0, a taper ratio of 0.40 , a 
leading-edge sweep of $30^{\circ}$, and no dihedral. The chord length at the side of the fuselage is 25.0 inches, resulting in a mean aerodynamic chord of 19.4 inches. The modular design and construction of the FAST-MAC model allows for changes to the leading edge, trailing edge, upper skin geometry (with or without engine simulators), and active or passive flow control technology. This modular construction of the FAST-MAC model is ideal for sweeping jet studies since it can be easily reconfigured with interchangeable actuators as shown in Figure 4.

Before discussing the results, an overview shall be given of the most important parameters governing the performance of a sweeping jet actuator. The equation shown below focuses on the actuator specific variables, but will relate to the wing performance variables when assessing the lift and drag performance of the system.

$$
\text { PERFORMANCE } E_{A C T U A T O R}=f c t n\left(\theta_{\text {SWEEP }}, f, U_{\text {EXIT }}, U_{\text {JET }}, \rho_{\text {JET }}, h_{\text {THROAT }}, z_{\text {THROAT }}, h_{\text {EXIT }}, z_{\text {EXIT }}, \alpha_{\text {EXIT }}\right)
$$

The introduction of several nondimensional parameter can decrease the number of parameters shown above which reduces the design space for actuator development. One of the critical coefficients is the momentum coefficient, $\mathrm{C} \mu$, which is shown in Equation 1. This quantity demonstrates the importance of the velocity ratio since its contribution is squared. $\mathrm{C} \mu$ can be further reduced to highlight the mass flow requirement as shown in Equation 2. To maintain a constant momentum coefficient and reduce mass flow, one must increase the jet velocity. For a fixed jet total temperature, the jet velocity is a function of nozzle pressure ratio (NPR) as seen in Equation 4. These characteristics are based on averaged steady conditions. Extending this to an unsteady jet configuration will substitute the steady velocity with an unsteady velocity characteristic that is traditionally the root mean square (rms) velocity. It is also accepted that the target momentum coefficient for the FAST-MAC effort will be different for high-lift and cruise conditions due to the separation control requirements for different flap and dynamic pressure conditions. The current effort will focus on maximizing the jet velocity that can be used in the momentum coefficient for future FAST-MAC tests.

$$
\begin{gathered}
C_{\mu}=\frac{\text { THRUST }}{q_{\infty} S}=\frac{2 h z}{\bar{c} b} \frac{\rho_{j e t}}{\rho_{\infty}} \frac{U_{j e t}^{2}}{U_{\infty}^{2}} \\
C_{\mu}=\frac{\text { THRUST }}{q_{\infty} S}=\frac{\dot{m} U_{j e t}}{q_{\infty} S} \\
\text { where } \\
\dot{m}=\rho_{J E T} U_{J E T}(h)(z) \\
U_{J E T}=\sqrt{\frac{2 \gamma R\left(T_{0_{J E T}}\right)\left(1-\left(\frac{1}{\gamma P R}\right)^{\frac{\gamma-1}{\gamma}}\right)}{\gamma-1}}
\end{gathered}
$$

The sweep frequency of the actuator is also critical to the performance benefits of the sweeping jet authority for boundary layer separation control ${ }^{19,20,21}$. As the jet sweeps from one side to the other, the propagation of the jet along a path is influenced by the frequency of the actuator. This can be characterized by the nondimensional frequency $f^{+}$.

$$
f^{+}=\frac{x(f)}{U_{\infty}}
$$

Since the characteristic length $\mathrm{x}$ and freestream velocity $\mathrm{U}_{\infty}$ are not defined for the quiescent case being discussed in this paper, a normalized nondimensional frequency will be used that is based on the average peak jet velocity and sweep frequency, shown in Equation 6. 


$$
f_{J E T}^{+} \approx \frac{f x}{U_{\infty}}=\frac{\Delta x_{T E}}{\lambda}
$$

where $\Delta \mathrm{x}_{\mathrm{TE}}$ is the distance from the throat to the trailing edge of the flap and $\lambda$ is the wavelength of the sweeping jet. Previous synthetic jet studies ${ }^{22}$ characterized $\mathrm{f}^{+}$to improve lift performance for a high-lift configurations. Typical lift coefficient improvements for those studies occurred for an $\mathrm{f}^{+}$range of 0.5 to 4.0. For a similar study ${ }^{23}$, the optimum $\mathrm{f}^{+}$occurs at 0.7. In general terms, $\mathrm{x}$ is a function of the relationship of the actuator position on the FAST-MAC flap, and it can be quantified by measuring the distance from the actuator exit to the trailing edge of the flap or to the separation location on the flap, whichever occurs first.

Designing the actuators for integration into the FAST-MAC model also requires the actuator to operate in the high dynamic pressure and high Reynolds number environment of the NTF. The FAST-MAC aft plenum cover is the only model component that requires modification, and it will house the actuator cartridges at a predefined spacing based on high-lift studies. The previous steady blowing FAST-MAC study utilized a constant slot height to chord ratio of 0.0022 resulting in a tapered slot. For the sweeping jet configuration, the exit height of each actuator will vary along the span from the inboard (root) towards the outboard (tip) until the slot reaches $54 \%$ of the span. The remainder of the actuators will have a fixed exit height of 0.040 inches due to limitations in the current fabrication technique. Table 1 highlights the dimensions of all thirty-nine actuators. The total exit area of the baseline sweeping jet configuration is $28 \%$ smaller than the steady blowing configuration, with a corresponding throat area reduction of $90 \%$. Table 2 shows the changes to actuator throat and diffuser exit areas for the cruise configuration.

The high-pressure air coupled with the thin model skin near the jet exit required a unique metal fabrication process for the actuators, as shown in Figure 5. The pneumatic actuator cartridges are built using a hybrid electrical discharge machining (EDM) / plating process. A 300-series stainless steel material is used for components that will be integrated with the nickel electroplating to provide strength and a thermally compatible base. The stainless steel surrounding structure and internal flow islands are machined via wire EDM to provide a light press fit with the erodible aluminum mandrel. The assembly is then nickel electroformed to build-up the desired finish contour thickness, and then it is machined to the correct planform and aerodynamic contour dimensions. At this point, the aluminum mandrel is etched away in a caustic bath, leaving the flow path embedded in the stainless steel/nickel structure. The stainless steel is pretreated before assembly to maximize adhesion to the nickel, producing a near homogeneous structure.

The turn around time for this fabrication process was weeks, so the optimization of the sweeping jet geometry used for the bench-top experiments utilized a stereolithography (SLA) rapid prototyping fabrication approach. It was determined that the manufacturing tolerance of the sweeping jet actuators could be maintained to within \pm 0.001 inch using either approach. This equated to $\pm 2.5 \%$ of the smallest throat dimension to be used in the FAST-MAC model. Both fabrication processes required a flushing or etching step to remove material from the internal flow path, and this step made the actuator susceptible to small perturbations that cause flow asymmetries or disturbances. These asymmetries and/or disturbances can interfere with the actuators ability to sweep, so each actuator must be evaluated prior to model installation.

The variations in diffuser geometries can be broken into four general categories:

1) Open diffusers with straight walls that are free of any internal obstructions,

2) Diamond-type diffusers having a diamond shape centered at the jet exit,

3) Wedge-type diffusers having a wedge centered at the jet exit, and

4) Coanda diffusers having curved walls with and without a wedge or diamond shape centered in the diffuser.

Each diffuser is characterized with different sweep angles, diffuser lengths, and throat areas that could be used in the FAST-MAC model. Figure 6 highlights the variations in the geometries of the exit diffuser configurations that are discussed in this paper. The diffuser inlet geometry (that includes the feedback legs) was held constant so that the diffuser exit geometry was the only variable parameter for the test series. Actuator A is the geometry that will be used in the FAST-MAC's baseline high-lift study, and it will be used as the standard for all comparisons.

\section{CFD Simulation}

Several recent computational fluid dynamics $(\mathrm{CFD})^{24,25}$ efforts have been used to characterize the internal flow through a sweeping jet actuator. To achieve an understanding of the actuator parameters needed for the FAST-MAC 
actuators, a CFD study was initiated to examine the salient features of the internal flow path including the jet-exit characteristics of an isolated actuator. The commercial FloEFD flow solver was chosen for convenience because the actuator geometries were developed using the ProE CAD design software. A description of the verification and validation of the FloEFD code is given in Reference 26. The CFD solver allows rapid grid generation in a Cartesian grid format with the choice of turbulence models, giving rapid time-accurate flow simulations measured in hours versus months for other time-accurate Navier-Stokes codes. Low-fidelity coarse solutions were typically analyzed in minutes, allowing a wide variety of candidate actuators to be screened. This process revealed configurations worthy of more detailed analysis and ultimately fabrication and experimental testing with the SLA prototypes. Only limited CFD comparisons obtained with the k- $\varepsilon$ turbulence model will be presented, as detailed grid refinement studies have not been completed.

\section{Experimental Setup}

The critical components of the sweeping jet actuator are identified in the coordinate system highlighted in Figure 7. A photograph of the bench-top setup of a single sweeping jet cartridge is shown in Figure 8. Since the focus of this study is on the influence of the diffuser and its performance, it is important to choose flow characteristics that can be scaled with geometry. In general, the jet decays along the $\mathrm{x}$-axis and will propagate along the time-varying flow angle as it sweeps from side to side. The sweep angle emanates from the point where the diffuser angles intersect with each other just upstream of the throat. Since this location cannot be seen or measured, the exit plane of the diffuser will be used as the zero reference location for all measurements. The downstream measurement plane is defined at the $\mathrm{x}$-position measured downstream of the diffuser exit and ratioed with the width of the diffuser $\left(\mathrm{Z}_{\mathrm{REF}}\right)$.

A block diagram of the bench-top instrument and measurement system is shown in Figure 9. The hot-wire and microphone data were simultaneously acquired at 102400 samples per second to achieve a $50 \mathrm{kHz}$ bandwidth. A single sensor hot-wire was used to survey the sweeping jet at several planes downstream of the exit plane. A stationary 0.25 -inch microphone was located 2.625 inches from the jet exit at $90^{\circ}$ along the Z-axis. Positioning the hot-wire sensor was accomplished with an X-Y-Z stepper motor system that had a resolution of \pm 5 microns. Zeroing the sensor was performed using a cathetometer.

Data repeatability was driven by the operator's ability to set nozzle pressure ratio (NPR) and total temperature. The total pressure was typically set for an NPR tolerance of \pm 0.01 of the desired NPR at the beginning of a hot-wire sweep. A typical variation of the total pressure during a sweep was \pm 0.05 psi. This resulted in the NPR varying \pm 0.002 through the run for the minimum NPR of 1.4. The system was also preheated prior to a run so that the total temperature could stabilize at $70^{\circ} \mathrm{F} \pm 1^{\circ} \mathrm{F}$. The total temperature was allowed to vary a maximum of $\pm 0.125^{\circ} \mathrm{F}$ during a sweep in an attempt to maintain hot-wire measurement integrity within its calibration space.

The time-dependent velocity field generated by the sweeping jet actuator is difficult to measure because of the spatial and temporal requirements associated with their small scale. The on-off nature of the jet as it sweeps by a fixed location requires a high-frequency measurement device that is robust enough to survive the large momentum variation. To achieve the spatial and frequency requirements of this effort, a 5-micron diameter hot-wire was initially used. However, the sensor failed when exposed to the large dynamic pressures of the jet at the exit plane of the actuator. A 50-micron diameter film was successfully substituted, and it could be operated over the entire design space of the experiments.

The hot-wire system was configured for a minimum $100 \mathrm{kHz}$ frequency response at Mach=0.9 and an overheat of 1.8. It is recognized that the hot-wire is sensitive to velocity, density, total temperature, and flow angle. It is assumed that the sweeping jet flowfield being measured in this study is dominated by vorticity (i.e., velocity), so density fluctuations are assumed to be negligible. To minimize the temperature sensitivity the total temperature is maintained by keeping the inlet temperature constant. The flow angle is also assumed negligible since the flow is normal to the sensor and the angle is small. Both the hot-wire calibrator system and the sweeping jet actuator system were fed with a temperature controlled air source to maintain jet total temperatures to $\pm 1^{\circ} \mathrm{F}$. The film calibration was broken into three segments to minimize data repeatability and measured error.

The calibration ranges shown in Figure 10(a) were:

a) low speed (Velocity $<100 \mathrm{ft} / \mathrm{sec}$ ),

b) medium speed $(100<$ Velocity $<800 \mathrm{ft} / \mathrm{sec})$ and

c) high speed (Velocity $>800 \mathrm{ft} / \mathrm{sec}$ ). 
The experimental repeatability of the hot-film calibration shown in Figure 10(b) indicates that the measured unsteady jet data has a measured repeatability of less than $\pm 1 \%$ of reading for the sweeping jet conditions of interest.

\section{Results}

In general, the velocity magnitude coupled with the sweep angle defines the authority needed to influence the local boundary layer condition at the jet exit. The magnitude authority established for steady blowing for the FAST-MAC cruise condition approaches the local Mach number near the jet exit. The optimal velocity ratio of jet velocity to the local freestream velocity at the jet exit of the model ranged from 1 to 1.53 . These results will serve as a target for the application of sweeping jets to the FAST-MAC model and establish the minimum and maximum blowing requirements for the sweeping jet.

\section{A. Using CFD to describe the internal flowfield of a sweeping jet}

Examples of the CFD sweeping jet time-dependent flow results are shown in Figure 11. These results highlight the oscillatory internal flow being driven by the feedback paths located on either side of the actuator. Figure 11a illustrates the internal velocity characteristics for one sweep cycle. This example of the internal flowfield begins $(A)$ with the jet stagnating at the lip, or beginning, of the contraction, thereby splitting the flow into two paths. The majority of the jet momentum moves along the starboard side contraction into the throat region and is vectored into the diffuser on the port side. The remaining portion of the flow enters the feedback leg moving toward the inlet where the flow has separated leaving a recirculating separation zone on the starboard side of the settling chamber. The next phase of the cycle $(B)$ shows the jet moving toward the port side of the settling chamber and stagnating onto the starboard side contraction. This results in a growth of the recirculating separation zone and reduces the momentum into the feedback leg. Phase $(C)$ shows the jet continuing to move toward the port wall of the settling chamber as the jet propagates through the contraction. The recirculating separation zone also propagates with the jet and continues to reduce the momentum into the starboard feedback leg. This results in an increase in throat velocity as the jet is vectored through the center of the throat creating a separation bubble on the port side of the diffuser. The next phase of the cycle $(D)$ shows the jet continuing to propagate through the settling chamber and attaching itself to the port side contraction. The recirculating separation region also propagates into the starboard side contraction and is reduced in strength. This results in no momentum being delivered to either feedback leg and a minimum interaction of the jet at the inlet. The flow is normal to the inlet plane resulting in a separated region forming on the port side of the settling chamber. It is also noted that the velocity magnitude at the throat is at a maximum at this point. The following phase of the cycle $(E)$ is where the jet fully attaches to the port side contraction creating the largest flow angle through the throat. We also see a portion of the flow entering the port feedback leg creating an interaction at the actuator inlet from the port side. As the jet in the lower section of the settling chamber propagates forward, the recirculating separation region in the upper portion of the starboard settling chamber is reduced as the port side separation grows. Finally, the jet attaches to the starboard wall of the diffuser $(F)$ creating the maximum jet flow angle but at a reduced average peak velocity exiting the diffuser. Observation of phases $(G)$ thru $(J)$ is similar to the above description but in the opposite direction. The density and pressure profiles shown in Figure 11(b) and 11(c) also highlight the time-dependent characteristics of the internal flow field of the sweeping jet and are used in the assessments of the different diffuser configurations.

\section{B. Comparison of experiment with CFD for nonsweeping jet}

To gain a better understanding of the nozzle efficiency and losses in the rapid diffuser, the jet velocity was characterized with the no sweeping motion using CFD and experiments. This was accomplished by blocking both of the feedback paths that set up the resonance associated with the oscillating motion of the jet. The efficiency of a wide-angle diffuser is characterized by the ratio of the steady jet velocity and throat velocity by projecting the jet along an angle that is referenced to the intersection of the diffuser angle just upstream of the throat as shown in Figure 12 for different NPRs. Ideally, the throat will be sonic at an NPR of 1.89. The data also highlights the velocity decay as it expands through the diffuser. For an ideal diffuser, the jet would expand to the limits of the diffuser, which would be $\pm 47.5^{\circ}$ for the actuator being evaluated. However, boundary layer separation occurs near the throat and limits the effective jet to approximately $\pm 10^{\circ}$. The flow angle for these conditions was normalized to the angle where the maximum velocity occurred. The bias was shown in Figure 12 to be fixed at angles that ranged from $+7^{\circ}$ to $+10.5^{\circ}$ for the experiment and $+3^{\circ}$ to $-1.5^{\circ}$ for the CFD data. The low frequency motion of the steady jet was not observed in the experiment as shown in the spectra in Figure 13. However, the CFD image shown in Figure 
14 identifies a low frequency motion for several NPRs and different phases of the time series. This motion is being driven by the variation of the velocity at the throat that is being influenced by the unsteady nature of the internal unsteady interactions at the actuator inlet. The experiment does show a high frequency coherent structure that is thought to be a coherent shear layer emanating from the throat/diffuser interface. The CFD time steps and grid resolution are not resolved well enough to capture this frequency.

\section{Scaling and salient features of sweeping jets}

As measurements are extended to the unsteady flow field of the sweeping jet, it is important to recognize that the jet translates by the fixed location of the hot-wire probe, thereby creating the appearance of a jet on and jet off condition as shown in Figure 15. The analysis of these data can be broken into averaged quantities and average peak quantities. These evaluations are accomplished at each point along the sweep by averaging the time history to obtain the average and using a probability density function (PDF) to determine the average peak velocity. These values can be used to determine the maximum and minimum velocity along the span of the actuator exit as a function of sweep angle.

The measured period of the jet at a fixed location is related to the jet width and sweep frequency ${ }^{27}$. The time histories for three spanwise locations at $\mathrm{X} / \mathrm{Z}_{\mathrm{REF}}=0.049$ illustrate the changing time dependent behavior of the jet. Typical sample periods were four seconds and acquired at 102400 samples per second. Examining the first 0.005 seconds of the time histories, one can see the on/off characteristic changes as it sweeps from one side to the other. The large dwell time near the outer edges of the sweep angle indicates that a $50 \%$ duty cycle exists. As the jet approaches the centerline of the diffuser, the jet transitions to a profile that is twice the frequency of the outer edges of the diffuser exit.

There is a high frequency coherent signal that rides on top of the main sweep frequency that is thought to be associated with a coherent structure in the jet shear layer that originates at the throat. The variation of this high frequency is also captured by the PDF and does not change with NPR. The PDF shown in Figure 15a was created using all four seconds of data. The average peak velocity of the jet is defined by the maximum PDF of $767 \mathrm{ft} / \mathrm{sec}$ for this example. The average peak velocity is lower at the extremes of the sweep (Figure 15a) than as the jet sweeps near or through the centerline of the diffuser exit as shown in Figure $15 \mathrm{~b}$ and $15 \mathrm{c}$. This is believed to be due to the influence of the reduction of the momentum through the throat as a portion of the internal jet momentum is directed through the feedback leg.

To examine the scalability of the actuators, a comparison of the averaged jet velocity profiles for two different size actuators (F and FF) are shown in Figure 16 for two downstream locations. The size of these actuators corresponds to the FAST-MAC inboard and tip locations, respectively. In general, the velocity results of the two scaled actuators are similar. While the two actuators have similar performance profiles, the larger actuator is more asymmetric than the smaller actuator. The cause of this asymmetry is unclear. Several possibilities exist, that could include small internal perturbations that bias the flow to one side, asymmetries in the fabrication of the actuator, or natural instabilities that bias or lock onto one side of the throat.

The schlieren images shown in Figure 17 highlight the coherent structures in the shear layer formed at the separated region located at the throat and diffuser interface. These small-scale structures are correlated to the high frequency fluctuations (typically $10 \mathrm{kHz}$ to $11 \mathrm{kHz}$ for the smaller actuators) that are superimposed on the jet velocity measured throughout this test series. This shear layer instability is related to the radius of the throat. The remainder of the paper will focus on the small-scale actuator.

\section{Comparison of high-lift and cruise actuators}

This section will be used to highlight the performance characteristics of actuators for the FAST-MAC cruise and high-lift applications. Note that all of the experiment comparisons made in this section are averaged hot-wire velocities made at a measurement plane that is downstream of the diffuser exit. The hot-wire measurement plane is located downstream of the diffuser exit at $20 \%$ of the spanwise opening of the actuator $\left(Z_{\mathrm{REF}}\right)$ unless otherwise noted. The reason for this location was to reduce the risk of sensor damage, but it also ensures that the measurements remain within the calibration of the hot-wire.

CFD results for actuator AA (designed for cruise conditions) at three NPR conditions are shown in Figure 18. The internal flow is consistent with actuator A (designed for low-speed high-lift conditions), and the sweep mechanism 
up to the throat does not seem to vary with NPR. The leading edge of the diamond located in the diffuser acts as a flow splitter and stabilizes the sweeping motion in the vicinity of the diamond. The similarities for the subsonic throat conditions are highlighted in Figure $18 \mathrm{a}$ and $18 \mathrm{~b}$ for $\mathrm{NPR}=1.4$ and $\mathrm{NPR}=1.8$. As the jet sweeps through the diffuser, the effective angle-of-attack on the diamond changes, resulting in a time-varying separation and reattachment on either side of the diamond. The average flow field at the diffuser exit is flat and does not vary until the jet reaches the wake of the diamond where the velocity magnitude is reduced. This reduction at the centerline of the actuator continues with increasing NPR until the throat reaches sonic conditions, resulting a near-zero velocity profile at the centerline. This reduction in the flow at the actuator centerline creates a bistable sweeping effect. Once the NPR is increased above 1.89 , the maximum average jet is constrained to approximately $\pm 20^{\circ}$.

The experimental performance comparisons for actuator AA (Diamond) and A (Open) are shown in Figure 19. Both of these actuators have a velocity distribution that is centered around the centerline of the actuator. Actuator AA consistently has a larger magnitude authority compared to actuator A by as much as $15 \%$ for low NPRs and $30 \%$ for the higher NPRs. The tradeoff for this improvement is a reduced sweep authority for NPR $<1.89$ and may impact the effectiveness of the designed actuator spacing. It is not clear what impact this tradeoff will have for the transonic cruise configuration of the FAST-MAC experiment.

Actuator AA has a maximum sweep authority that is consistent with the diffuser angle of $\pm 35^{\circ}$. The ratio of the average velocity to the ideal throat velocity for NPR $<1.89$ varies from 0.25 to $0.30(216 \mathrm{ft} / \mathrm{sec} \mathrm{to} 320 \mathrm{ft} / \mathrm{sec}) \mathrm{over}$ a range of sweep angles $-35^{\circ}<\theta<-10^{\circ}$ and $10^{\circ}<\theta<35^{\circ}$ before entering the wake region downstream of the diamond. The minimum average velocity in the wake region occurs at $\theta=0^{\circ}$ and ranges from 0 to 0.14 . For the subsonic NPRs, the velocity ratio in the wake region varies from 0.10 to 0.14 (constant at $110 \mathrm{ft} / \mathrm{sec}$ ), which is consistently equal to or higher than the centerline velocity ratio of actuator A. The actuator AA velocity ratio for NPR $>1.89$ is influenced by shock formations within the jet. The velocity ratio for these conditions approach 0.65 at the higher NPRs. The average velocity for this condition is $916 \mathrm{ft} / \mathrm{sec}$ and the average peak velocity is $1100 \mathrm{ft} / \mathrm{sec}$, which could be enough to influence the transonic flow conditions on the flap of the FAST-MAC configuration. There is an asymmetry in the velocity magnitude along the span of the actuator, and it grows with increasing NPR. This subtle asymmetry is expected to be acceptable for use in the FAST-MAC cruise and high-lift system.

The sweep authority of actuator A has a range of $\pm 45^{\circ}$ for an NPR of 1.4 to 1.8 . This is consistent with the maximum diffuser angle of $\pm 47.5^{\circ}$. However, the sweep authority decreases for NPR $>1.89$. As NPR approaches 4.0 , the sweep authority decreases to $\pm 12.75^{\circ}$. The ratio of the average velocity to the ideal throat velocity is constant at 0.106 ( 82 $\mathrm{ft} / \mathrm{sec}$ to $100 \mathrm{ft} / \mathrm{sec}$ ) over a range of sweep angles $\theta= \pm 30^{\circ}$. As the jet sweeps to the outboard limits of the diffuser ($50^{\circ}<\theta<-30^{\circ}$ and $\left.30^{\circ}<\theta<50^{\circ}\right)$, this ratio increases to $0.141(121 \mathrm{ft} / \mathrm{sec}$ to $171 \mathrm{ft} / \mathrm{sec})$, indicating that the jet dwells longer at the outer edges of the sweep even though the maximum velocity decreases as indicated in the CFD results. As the NPR increases above sonic throat conditions, this velocity ratio increases to 0.345 (535 $\mathrm{ft} / \mathrm{sec}) \mathrm{but}$ the sweep angle is constrained to $\pm 12.75^{\circ}$. It is also noticed that there is an asymmetry in the velocity magnitude along the span of the actuator, and it grows with increasing NPR. This subtle asymmetry is expected to be acceptable for use in the FAST-MAC high-lift system.

The variation in the time-dependent flows for actuator AA as the jet sweeps through different phases of the cycle is shown for two NPRs in Figure 20. Both the average peak velocity and averaged velocity for the NPR $=1.6$ condition do not significantly vary for most of the sweep cycle until it reaches the wake region of the diamond as shown in Figures 20 a-c. This is also reflected in the PDF data shown in Figure 21a. However, as the NPR increases, the recovery of the jet is altered for an NPR of 4.0 as shown in Figure $20 \mathrm{~d}-\mathrm{f}$. The character of the jet at $\theta=18.0^{\circ}$ (maximum magnitude authority shown in Figure 20d) has transitioned to a sinusoidal-like function. The average and average peak velocities are closer in magnitude at the maximum velocity authority as shown in Figure 21 b. As the jet moves toward the centerline, the jet begins to recover to the on-off behavior that is characteristic of actuator A. However, when the jet approaches $\theta= \pm 5^{\circ}$, the blockage of the diamond splitter creates a wake that results in a nearzero average and average peak velocity.

The sweep frequencies and corresponding sound pressure levels (SPLs) for the two small-scale actuators A and AA are shown in Figure 22. The measured SPL are order-of-magnitude estimates of the noise generated by a single actuator. These levels will become part of NASA efforts to improve performance while decreasing noise propagated to the community. Once the performance benefits are established on the FAST-MAC model in the NTF, these measurements should be repeated in an anechoic chamber. The frequency of the actuator is correlated to its physical 
size, which includes the throat area, the length of the plenum, and the volume of the feedback legs. The internal geometry of the two actuators were the same with the exception of the throat area and the diffuser angles, i.e., the length of the plenum and volume of the feedback legs were held constant in an attempt to keep the internal time of flight and internal flow interactions constant for a specific NPR. The corresponding nondimensional frequencies are shown in Figure 23 for two wind tunnel conditions associated with the high-lift and cruise Mach numbers $(\mathrm{M}=0.2$ and 0.85 , respectively) for the FAST-MAC model. This example is for the actuator located near the wing tip and has a, $\mathrm{X}_{\mathrm{TE}}$ of 1.75 inches. The sweep frequency of the two small-scale actuators differs due to the difference in mass flow through the throat as seen in Figure 23. The impact of local density variation on sweep frequency is not clear, so the jet temperature will be held constant for the FAST-MAC test series.

Recall that actuator AA has twice the throat area as actuator A, and the ideal mass flow is proportional to throat size for a given total $\mathrm{Re}_{\mathrm{C}}$ as shown in Figure 24. Integration of actuator AA into the outboard span of the model will replace 19 actuators that will increase the total throat area by $33.4 \%$. The estimated mass flow requirements for the cruise condition is lower than the high-lift condition due to lower local static pressures at the jet exit. It is recognized that the mass flow through the actuator will increase as the wind-tunnel density increases for the FAST-MAC test (Figure 24b). Steady blowing results from Reference 1 indicated that the end of separation control and beginning of super-circulation occurs at a momentum coefficient of approximately 0.15 for the $30^{\circ}$ flap and 0.40 for the $60^{\circ}$ flap. The estimated momentum coefficients for the sweeping jets (shown in Figure 25a) indicates that the momentum required to achieve separation control in the high-lift configuration should be adequate using these actuators. Steady

blowing at the outboard portion of the cruise flap resulted in drag benefits for $\mathrm{C}_{\mu}>0.005(\mathrm{NPR}=1.73)$ at design

conditions and $\mathrm{C}_{\mu}>0.002$ (NPR=1.2) for off-design conditions. The estimated momentum coefficients for the sweeping jets shown in Figure $25 \mathrm{~b}$ indicate that the momentum required to achieve a drag benefit is marginal.

While actuators A and AA are the actuators that will be used for the FAST-MAC test, several alternate diffuser configurations were evaluated and rejected. Actuator B extended the diffuser length and maximized the exit. This reduced the diffuser angle from $95^{\circ}$ to $86^{\circ}$, resulting in a smaller sweep authority as shown in Figure $26 \mathrm{~b}$. While the velocity magnitude authority was similar to actuator $A$, this configuration was rejected because of the reduced sweep angle. Actuator BB was similar in performance to actuator B, but resulted in an asymmetric behavior that is unacceptable. Actuator $\mathrm{C}$ shown in Figure $27 \mathrm{~b}$ was designed to reduce the exit area and increase the velocity authority. While slight increases were achieved in the velocity authority for this configuration, the sweep authority variations were reduced compared to actuators with larger diffuser angles. The average velocity profiles for this configuration also showed that there was an asymmetry for actuator $\mathrm{C}$ and $\mathrm{CC}$ that was unacceptable. The Coanda actuator D shown in Figure 28b was intended to start with the narrow diffuser geometry of actuator C and curve the diffuser wall to achieve a larger sweep authority. The sweep authority for actuator D was improved when compared to actuator $\mathrm{C}$ for $\mathrm{NPR}<1.89$, but became asymmetric for $\mathrm{NPR}>1.89$ and ultimately stopped sweeping. Similarly, actuator DD highlighted in Figure 28a increased the sweep authority for NPR $<1.89$ compared to actuator CC, but also became asymmetric and unacceptable. Actuator $\mathrm{E}$ was designed with a reduced diffuser angle compared to actuator A, and this diffuser reduced the variation in sweep authority at the expense of velocity authority for NPR $>1.89$ as shown in Figure 29b. Placing a wedge in the diffuser (actuator EE) reduced the exit area and was intended to increase the velocity authority of actuator E, but this did not occur. The overall authority of actuator EE (shown in Figure 29a) was rejected due to the large bi-stable flow resulting from the large wake deficit of the wedge splitter.

\section{Concluding Remarks}

AFC has been shown to be beneficial for high-lift and cruise configurations for the FAST-MAC model using steady blowing. Application of a sweeping jet configuration is expected to manage separation on the flap for both the highlift and cruise configurations as well. The reduction of the sweeping jet actuator throat area compared to the fullspan slot of the steady blowing configuration of the FAST-MAC model is expected to significantly reduce the mass flow requirements for active separation control on the flap. The performance of the sweeping jet can be influenced by the diffuser configuration as demonstrated throughout this paper. CFD and bench top experiments characterized in this paper helped identify physics that influence the design of an effective sweeping jet actuator. Designing an optimal diffuser configuration for both the high-lift and cruise configuration requires tradeoffs of the velocity authority and sweep authority of the actuator. The tradeoffs identified in this paper may not be fully optimized for the FAST-MAC model, but are thought to have the required characteristics to manage the separation control regime 
of the tested configurations. Actuator A and AA have been selected as the path forward to the next FAST-MAC test in NTF. Other diffuser configurations were rejected due to poor performance or asymmetries in the exit flowfield.

\section{Acknowledgements}

The effort has been supported by the Advanced Air Transport Technology project. Special thanks are given to Scott Anders, Susan Wilz, and Sally Viken for their support and latitude in the design and testing of the actuators to be used in the FAST-MAC model. A special thank you is extended to the instrumentation technicians (Ron Rauschenbach, Mike Czarnecki, James Montgomery, and Bill Goad) and model technicians (Roy Armstrong and James Oshaughnessy) at the NTF facility for the integration and troubleshooting of the instrumentation and actuator modifications needed during these experiments. Special gratitude is extended to Brett Bathel for his Schlieren efforts used to help characterize the internal flow of the actuators.

Table 1. Actuator A dimensions for the FAST-MAC model.

\begin{tabular}{|c|c|c|c|c|c|c|c|}
\hline $\begin{array}{c}\text { BASELINE } \\
\text { ACTUATOR } \\
\text { A }\end{array}$ & $\begin{array}{c}\text { SPAN } \\
\begin{array}{c}\text { LOCATION } \\
\text { (in) }\end{array}\end{array}$ & $\begin{array}{l}\text { THROAT } \\
\text { HEIGHT } \\
\text { (in) }\end{array}$ & $\begin{array}{c}\text { THROAT } \\
\text { WIDTH } \\
\text { (in) }\end{array}$ & $\begin{array}{c}\text { THROAT } \\
\text { AREA } \\
\left.\text { (in }^{2}\right) \\
\end{array}$ & $\begin{array}{c}\text { EXIT } \\
\text { HEIGHT } \\
\text { (in) }\end{array}$ & $\begin{array}{c}\text { EXIT } \\
\text { WIDTH } \\
\text { (in) }\end{array}$ & $\begin{array}{c}\text { EXIT } \\
\text { AREA } \\
\left(\text { in }^{2}\right)\end{array}$ \\
\hline $1-2$ & 1.250 & 0.0690 & 0.1380 & 0.00952 & 0.0690 & 0.915 & 0.0631 \\
\hline $1-3$ & 2.738 & 0.0675 & 0.1350 & 0.00911 & 0.0675 & 0.915 & 0.0618 \\
\hline $1-4$ & 3.863 & 0.0659 & 0.1318 & 0.00869 & 0.0659 & 0.915 & 0.0603 \\
\hline $1-5$ & 5.306 & 0.0645 & 0.1290 & 0.00832 & 0.0645 & 0.915 & 0.0590 \\
\hline $1-6$ & 6.431 & 0.0630 & 0.1260 & 0.00794 & 0.0630 & 0.915 & 0.0576 \\
\hline $1-7$ & 7.957 & 0.0614 & 0.1228 & 0.00754 & 0.0614 & 0.915 & 0.0562 \\
\hline $1-8$ & 9.082 & 0.0598 & 0.1196 & 0.00715 & 0.0598 & 0.891 & 0.0533 \\
\hline $2-1$ & 10.878 & 0.0582 & 0.1164 & 0.00677 & 0.0582 & 0.816 & 0.0475 \\
\hline $2-2$ & 12.243 & 0.0566 & 0.1132 & 0.00641 & 0.0566 & 0.816 & 0.0462 \\
\hline $2-3$ & 13.607 & 0.0549 & 0.1098 & 0.00603 & 0.0549 & 0.816 & 0.0448 \\
\hline $2-4$ & 14.831 & 0.0533 & 0.1066 & 0.00568 & 0.0533 & 0.796 & 0.0424 \\
\hline $2-5$ & 16.176 & 0.0517 & 0.1034 & 0.00535 & 0.0517 & 0.766 & 0.0396 \\
\hline $2-6$ & 17.417 & 0.0501 & 0.1002 & 0.00502 & 0.0501 & 0.746 & 0.0374 \\
\hline $2-7$ & 18.744 & 0.0484 & 0.0968 & 0.00469 & 0.0484 & 0.720 & 0.0349 \\
\hline $2-8$ & 20.150 & 0.0468 & 0.0936 & 0.00438 & 0.0468 & 0.696 & 0.0326 \\
\hline 3-1 & 21.680 & 0.0452 & 0.0904 & 0.00409 & 0.0452 & 0.596 & 0.0269 \\
\hline $3-2$ & 22.506 & 0.0442 & 0.0884 & 0.00391 & 0.0442 & 0.584 & 0.0258 \\
\hline $3-3$ & 23.332 & 0.0431 & 0.0862 & 0.00372 & 0.0431 & 0.584 & 0.0251 \\
\hline $3-4$ & 24.405 & 0.0421 & 0.0842 & 0.00354 & 0.0421 & 0.574 & 0.0242 \\
\hline $3-5$ & 25.155 & 0.0410 & 0.0820 & 0.00336 & 0.0410 & 0.571 & 0.0234 \\
\hline $3-6$ & 25.905 & 0.0400 & 0.0800 & 0.00320 & 0.0400 & 0.586 & 0.0234 \\
\hline $3-7$ & 26.971 & 0.0400 & 0.0800 & 0.00320 & 0.0400 & 0.586 & 0.0234 \\
\hline $3-8$ & 27.721 & 0.0400 & 0.0800 & 0.00320 & 0.0400 & 0.586 & 0.0234 \\
\hline $3-9$ & 28.471 & 0.0400 & 0.0800 & 0.00320 & 0.0400 & 0.586 & 0.0234 \\
\hline $3-10$ & 29.545 & 0.0400 & 0.0800 & 0.00320 & 0.0400 & 0.586 & 0.0234 \\
\hline $3-11$ & 30.374 & 0.0400 & 0.0800 & 0.00320 & 0.0400 & 0.586 & 0.0234 \\
\hline $3-12$ & 31.203 & 0.0400 & 0.0800 & 0.00320 & 0.0400 & 0.586 & 0.0234 \\
\hline $4-1$ & 32.605 & 0.0400 & 0.0800 & 0.00320 & 0.0400 & 0.586 & 0.0234 \\
\hline $4-2$ & 33.431 & 0.0400 & 0.0800 & 0.00320 & 0.0400 & 0.586 & 0.0234 \\
\hline $4-3$ & 34.257 & 0.0400 & 0.0800 & 0.00320 & 0.0400 & 0.586 & 0.0234 \\
\hline 4-4 & 35.328 & 0.0400 & 0.0800 & 0.00320 & 0.0400 & 0.586 & 0.0234 \\
\hline $4-5$ & 36.078 & 0.0400 & 0.0800 & 0.00320 & 0.0400 & 0.586 & 0.0234 \\
\hline $4-6$ & 36.828 & 0.0400 & 0.0800 & 0.00320 & 0.0400 & 0.586 & 0.0234 \\
\hline $4-7$ & 37.897 & 0.0400 & 0.0800 & 0.00320 & 0.0400 & 0.586 & 0.0234 \\
\hline $4-8$ & 38.647 & 0.0400 & 0.0800 & 0.00320 & 0.0400 & 0.586 & 0.0234 \\
\hline $4-9$ & 39.397 & 0.0400 & 0.0800 & 0.00320 & 0.0400 & 0.586 & 0.0234 \\
\hline $4-10$ & 40.472 & 0.0400 & 0.0800 & 0.00320 & 0.0400 & 0.586 & 0.0234 \\
\hline $4-11$ & 41.292 & 0.0400 & 0.0800 & 0.00320 & 0.0400 & 0.586 & 0.0234 \\
\hline $4-12$ & 42.112 & 0.0400 & 0.0800 & 0.00320 & 0.0400 & 0.586 & 0.0234 \\
\hline
\end{tabular}

Table 2. Actuator AA dimensions for the FAST-MAC model.

\begin{tabular}{|c|c|c|c|c|c|c|c|}
\hline CRUISE & SPAN & THROAT & THROAT & THROAT & EXIT & EXIT & EXIT \\
\hline $\begin{array}{c}\text { ACTUATOR } \\
\text { AA }\end{array}$ & $\begin{array}{c}\text { LOCATION } \\
\text { (in) }\end{array}$ & $\begin{array}{l}\text { HEIGHT } \\
\text { (in) }\end{array}$ & $\begin{array}{l}\text { WIDTH } \\
\text { (in) }\end{array}$ & $\begin{array}{c}\text { AREA } \\
\left(\text { in }^{2}\right) \\
\end{array}$ & $\begin{array}{c}\text { HEIGHT } \\
\text { (in) }\end{array}$ & $\begin{array}{l}\text { WIDTH } \\
\text { (in) }\end{array}$ & $\begin{array}{l}\text { AREA } \\
\left(\text { in }^{2}\right)\end{array}$ \\
\hline $1-2$ & 1.250 & 0.0690 & 0.1380 & 0.00952 & 0.0690 & 0.915 & 0.0631 \\
\hline $1-3$ & 2.738 & 0.0675 & 0.1350 & 0.00911 & 0.0675 & 0.915 & 0.0618 \\
\hline $1-4$ & 3.863 & 0.0659 & 0.1318 & 0.00869 & 0.0659 & 0.915 & 0.0603 \\
\hline $1-5$ & 5.306 & 0.0645 & 0.1290 & 0.00832 & 0.0645 & 0.915 & 0.0590 \\
\hline $1-6$ & 6.431 & 0.0630 & 0.1260 & 0.00794 & 0.0630 & 0.915 & 0.0576 \\
\hline $1-7$ & 7.957 & 0.0614 & 0.1228 & 0.00754 & 0.0614 & 0.915 & 0.0562 \\
\hline $1-8$ & 9.082 & 0.0598 & 0.1196 & 0.00715 & 0.0598 & 0.891 & 0.0533 \\
\hline $2-1$ & 10.878 & 0.0582 & 0.1164 & 0.00677 & 0.0582 & 0.816 & 0.0475 \\
\hline $2-2$ & 12.243 & 0.0566 & 0.1132 & 0.00641 & 0.0566 & 0.816 & 0.0462 \\
\hline $2-3$ & 13.607 & 0.0549 & 0.1098 & 0.00603 & 0.0549 & 0.816 & 0.0448 \\
\hline $2-4$ & 14.831 & 0.0533 & 0.1066 & 0.00568 & 0.0533 & 0.796 & 0.0424 \\
\hline $2-5$ & 16.176 & 0.0517 & 0.1034 & 0.00535 & 0.0517 & 0.766 & 0.0396 \\
\hline $2-6$ & 17.417 & 0.0501 & 0.1002 & 0.00502 & 0.0501 & 0.746 & 0.0374 \\
\hline $2-7$ & 18.744 & 0.0484 & 0.0968 & 0.00469 & 0.0484 & 0.720 & 0.0349 \\
\hline $2-8$ & 20.150 & 0.0468 & 0.0936 & 0.00438 & 0.0468 & 0.696 & 0.0326 \\
\hline $3-1$ & 21.680 & 0.0452 & 0.0904 & 0.00409 & 0.0452 & 0.596 & 0.0269 \\
\hline $3-2$ & 22.506 & 0.0442 & 0.0884 & 0.00391 & 0.0442 & 0.584 & 0.0258 \\
\hline $3-3$ & 23.332 & 0.0431 & 0.0862 & 0.00372 & 0.0431 & 0.584 & 0.0251 \\
\hline 3-4 & 24.405 & 0.0421 & 0.0842 & 0.00354 & 0.0421 & 0.574 & 0.0242 \\
\hline $3-5$ & 25.155 & 0.0410 & 0.0820 & 0.00336 & 0.0410 & 0.571 & 0.0234 \\
\hline 3-6 & 25.905 & 0.0800 & 0.0800 & 0.00640 & 0.0400 & 0.566 & 0.0227 \\
\hline $3-7$ & 26.971 & 0.0800 & 0.0800 & 0.00640 & 0.0400 & 0.566 & 0.0227 \\
\hline $3-8$ & 27.721 & 0.0800 & 0.0800 & 0.00640 & 0.0400 & 0.566 & 0.0227 \\
\hline $3-9$ & 28.471 & 0.0800 & 0.0800 & 0.00640 & 0.0400 & 0.566 & 0.0227 \\
\hline $3-10$ & 29.545 & 0.0800 & 0.0800 & 0.00640 & 0.0400 & 0.566 & 0.0227 \\
\hline $3-11$ & 30.374 & 0.0800 & 0.0800 & 0.00640 & 0.0400 & 0.566 & 0.0227 \\
\hline $3-12$ & 31.203 & 0.0800 & 0.0800 & 0.00640 & 0.0400 & 0.566 & 0.0227 \\
\hline $4-1$ & 32.605 & 0.0800 & 0.0800 & 0.00640 & 0.0400 & 0.566 & 0.0227 \\
\hline $4-2$ & 33.431 & 0.0800 & 0.0800 & 0.00640 & 0.0400 & 0.566 & 0.0227 \\
\hline $4-3$ & 34.257 & 0.0800 & 0.0800 & 0.00640 & 0.0400 & 0.566 & 0.0227 \\
\hline $4-4$ & 35.328 & 0.0800 & 0.0800 & 0.00640 & 0.0400 & 0.566 & 0.0227 \\
\hline $4-5$ & 36.078 & 0.0800 & 0.0800 & 0.00640 & 0.0400 & 0.566 & 0.0227 \\
\hline $4-6$ & 36.828 & 0.0800 & 0.0800 & 0.00640 & 0.0400 & 0.566 & 0.0227 \\
\hline $4-7$ & 37.897 & 0.0800 & 0.0800 & 0.00640 & 0.0400 & 0.566 & 0.0227 \\
\hline $4-8$ & 38.647 & 0.0800 & 0.0800 & 0.00640 & 0.0400 & 0.566 & 0.0227 \\
\hline $4-9$ & 39.397 & 0.0800 & 0.0800 & 0.00640 & 0.0400 & 0.566 & 0.0227 \\
\hline $4-10$ & 40.472 & 0.0800 & 0.0800 & 0.00640 & 0.0400 & 0.566 & 0.0227 \\
\hline $4-11$ & 41.292 & 0.0800 & 0.0800 & 0.00640 & 0.0400 & 0.566 & 0.0227 \\
\hline $4-12$ & 42.112 & 0.0800 & 0.0800 & 0.00640 & 0.0400 & 0.566 & 0.0227 \\
\hline
\end{tabular}




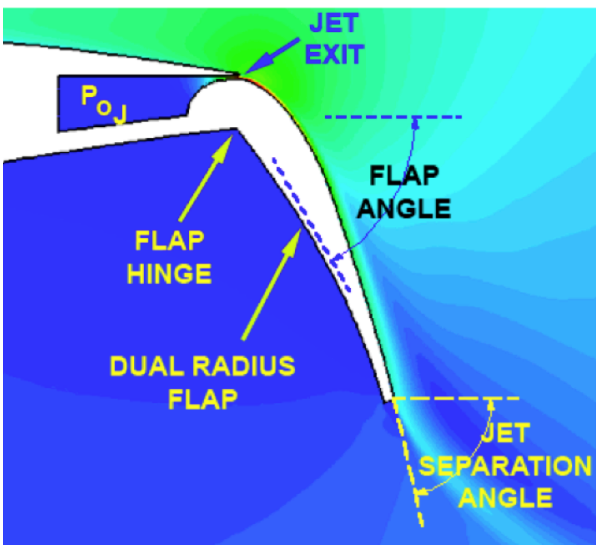

Figure 1. Circulation control concept for boundary layer separation control on a $60^{\circ}$

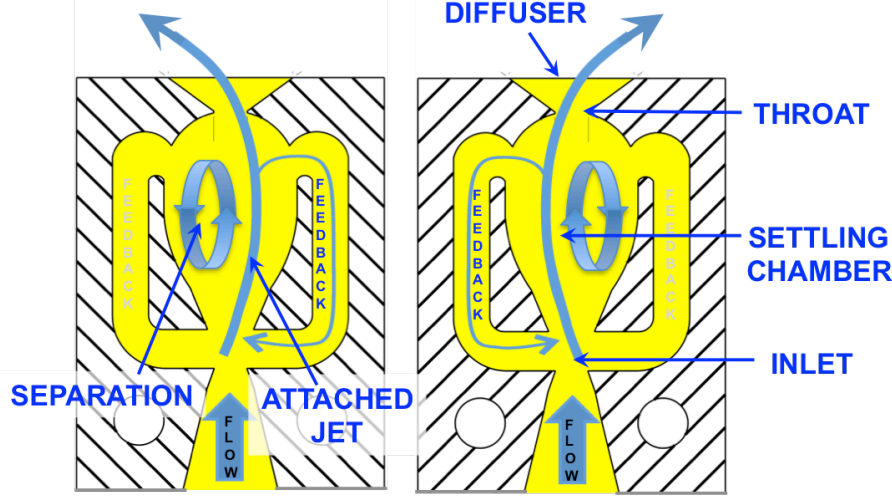

Figure 2. Fundamental characteristics of a sweeping jet illustrating the two extremes of the jet position and the feedback passages that drive the oscillatory motion. hinged flap.

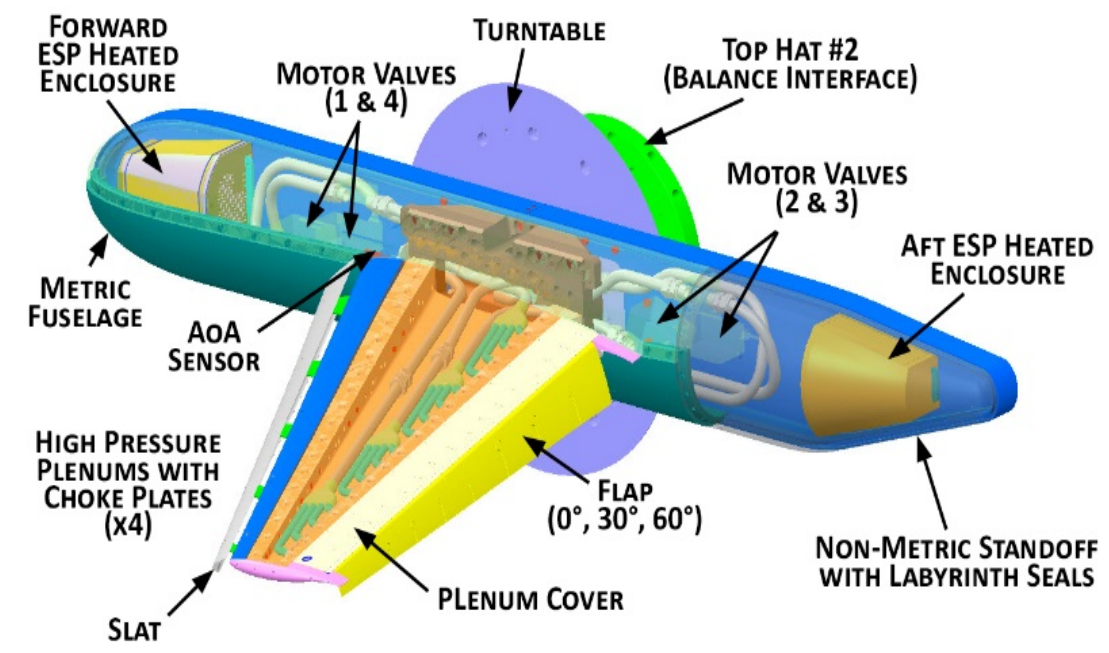

Figure 3. Cutaway view of the FAST-MAC model in high-lift mode, highlighting multiple internal flow paths.

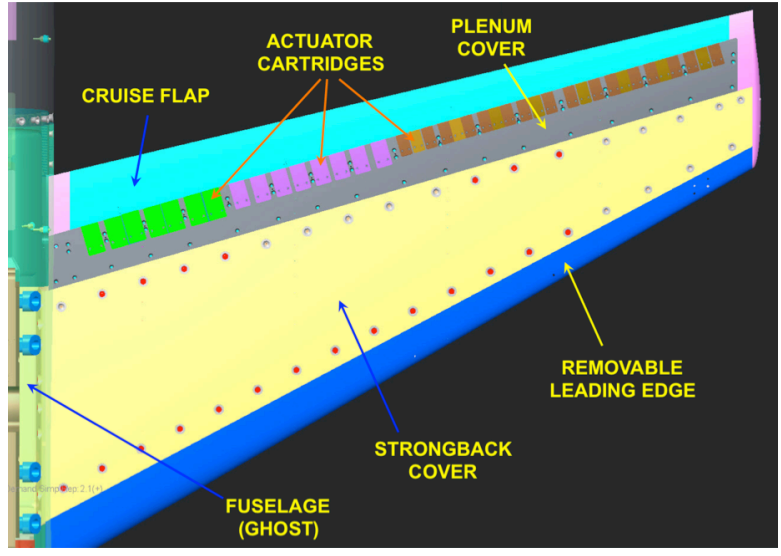

Figure 4. Exit flow paths for 39 sweeping jets along the span of the FAST-MAC model.

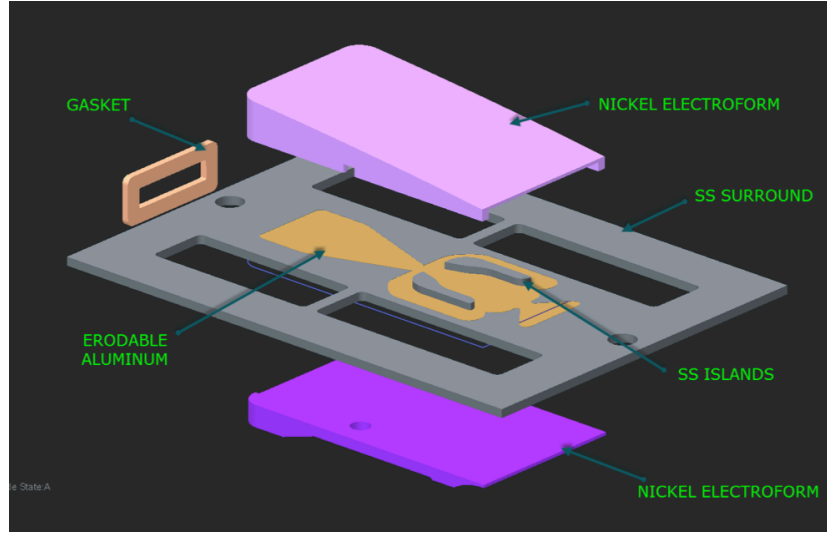

Figure 5. Expanded view of the plating configuration for the sweeping jet cartridge. 


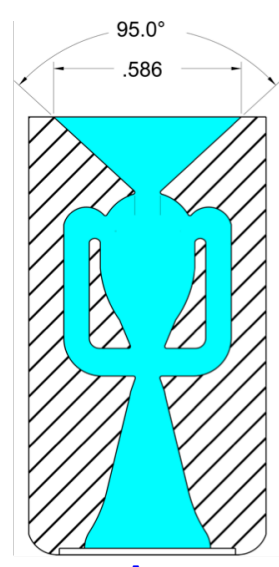

A

THROAT

0.040 "x 0.080"

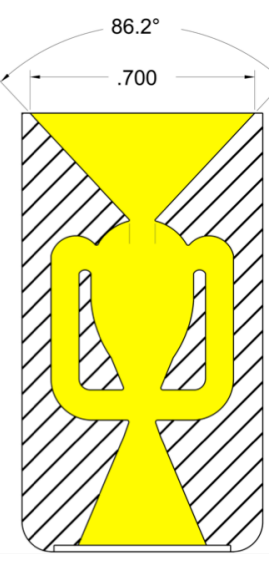

B

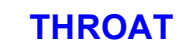

0.080 " $\times 0.080$ "

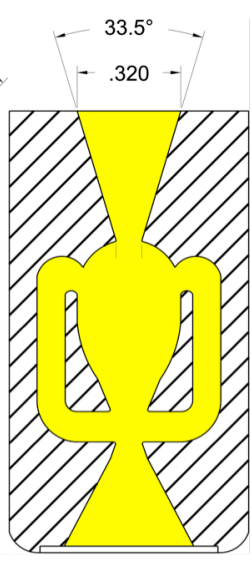

C

THROAT

0.080 " 0.080 "

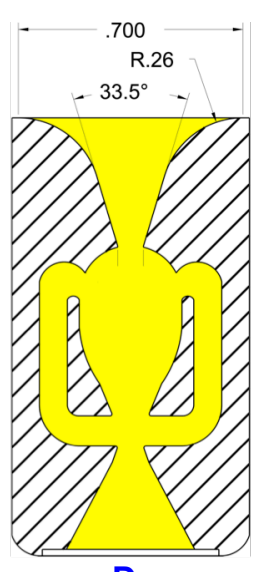

D

THROAT

0.080 " 0.080 "

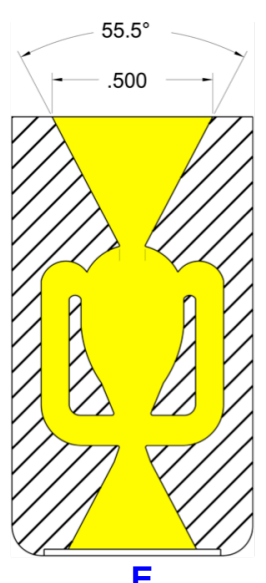

THROAT 0.080 "x0.080"

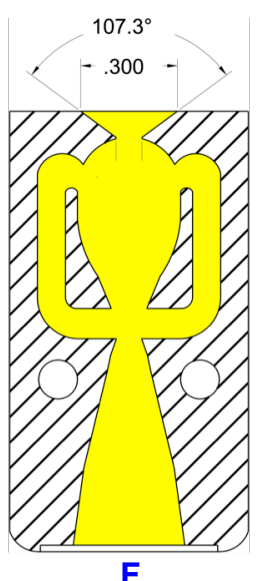

THROAT

0.040 " $\times 0.080$ "

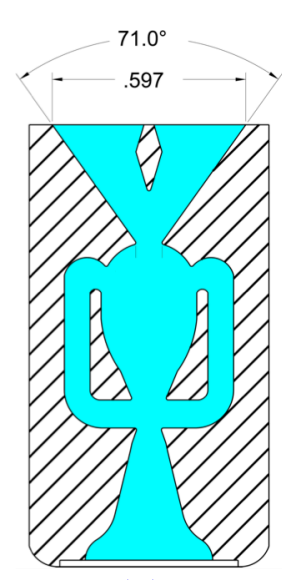

AA

THROAT

0.080 "x 0.080 "

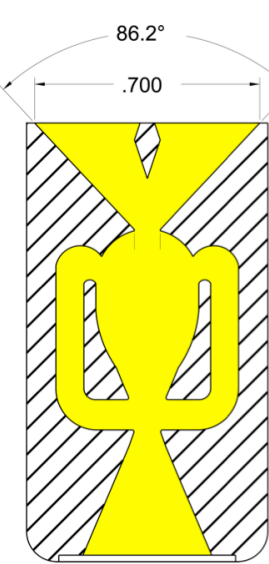

BB

THROAT

0.080 " $\times 0.080$ "

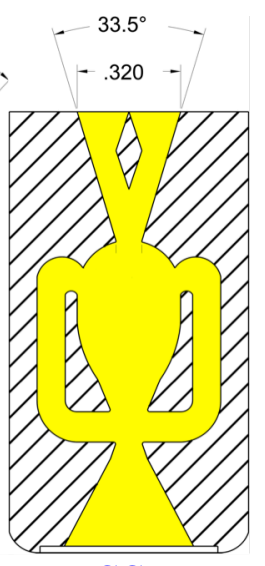

CC

THROAT

0.080 " 0.080 "

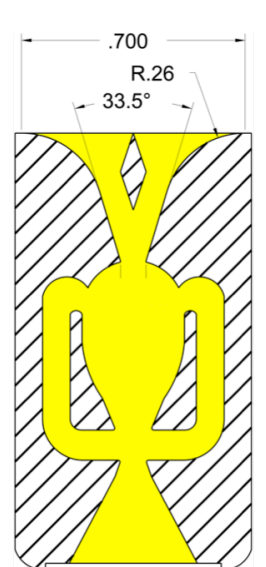

DD

THROAT

0.080 " $\times 0.080$ "

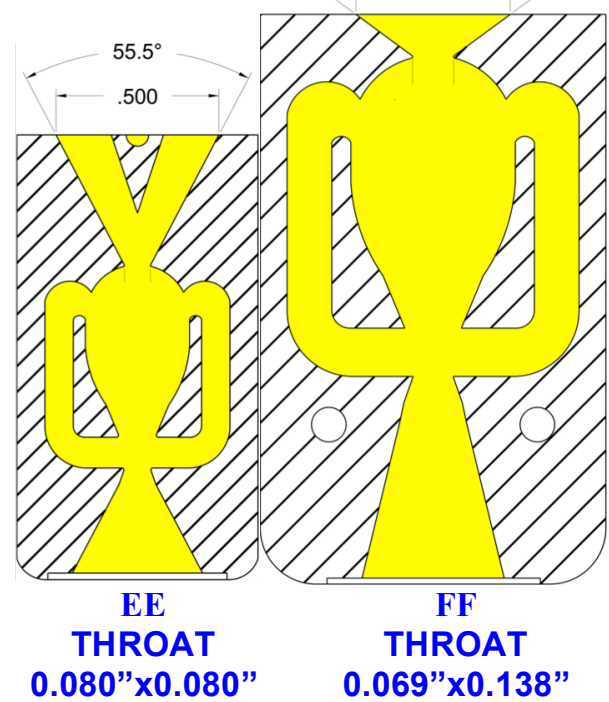

Figure 6. Diffuser variations for sweeping jet actuators.

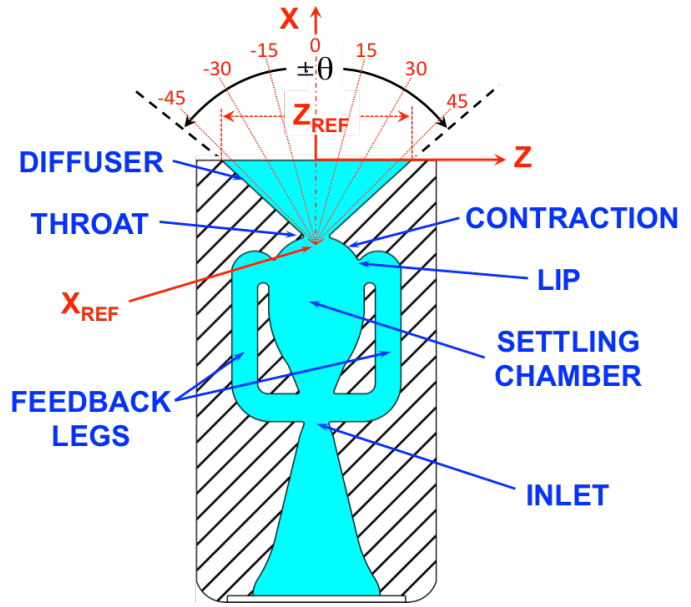

Figure 7. Sweeping jet components and coordinate system.

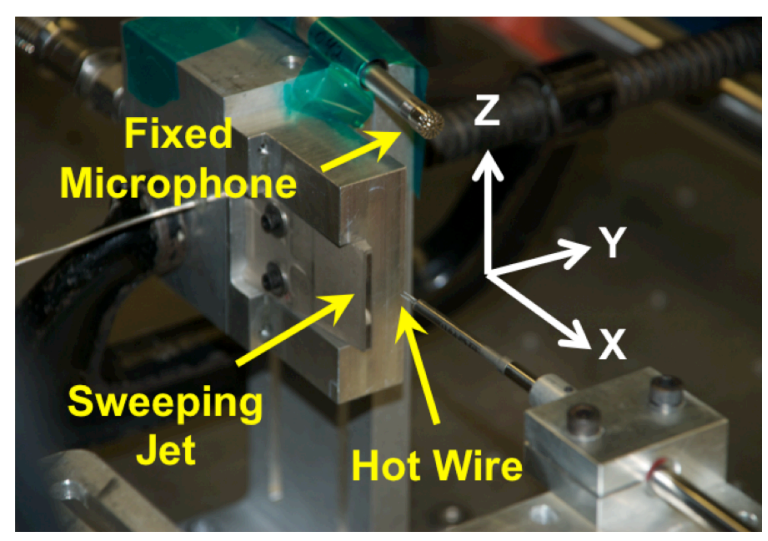

Figure 8. Photograph of bench-top sweeping jet measurement system. 


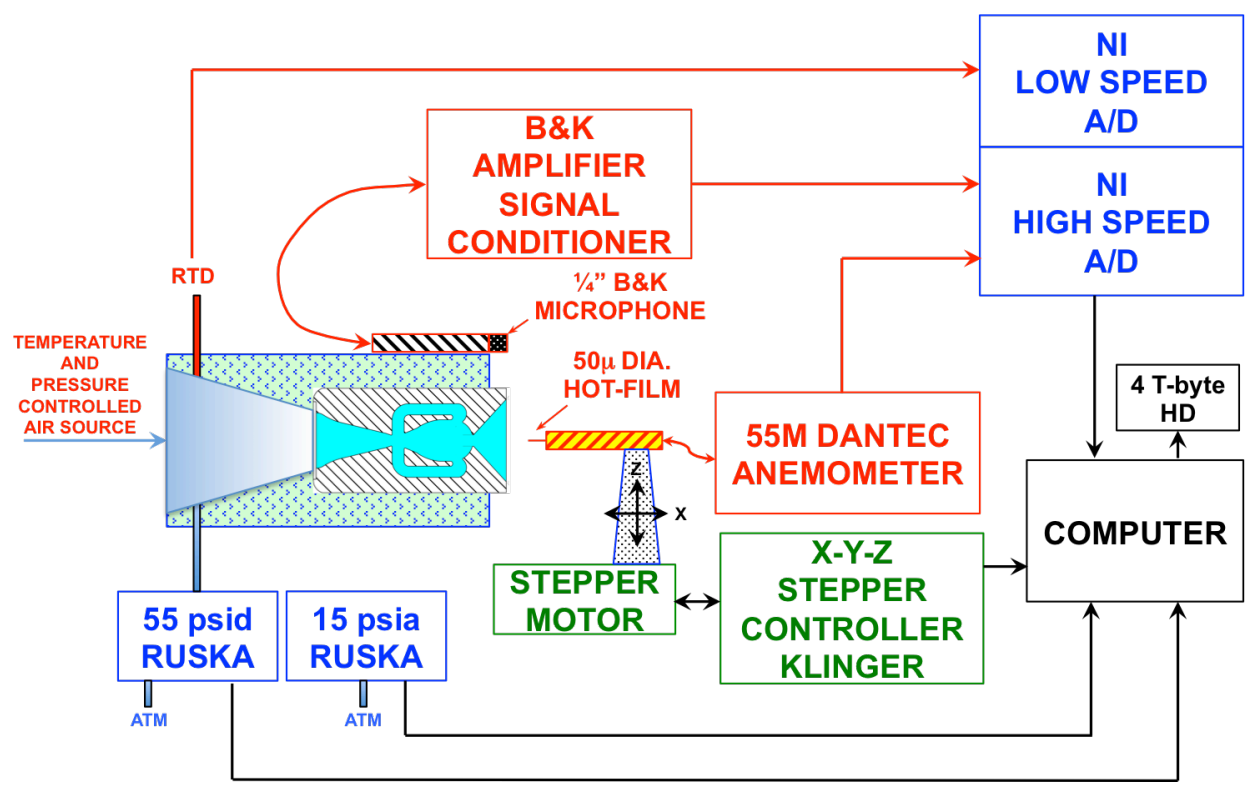

Figure 9. Block diagram of data acquisition system

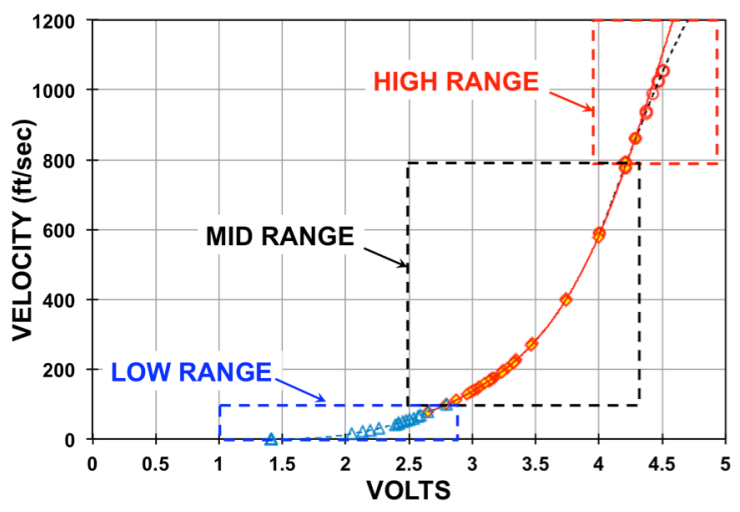

(a)

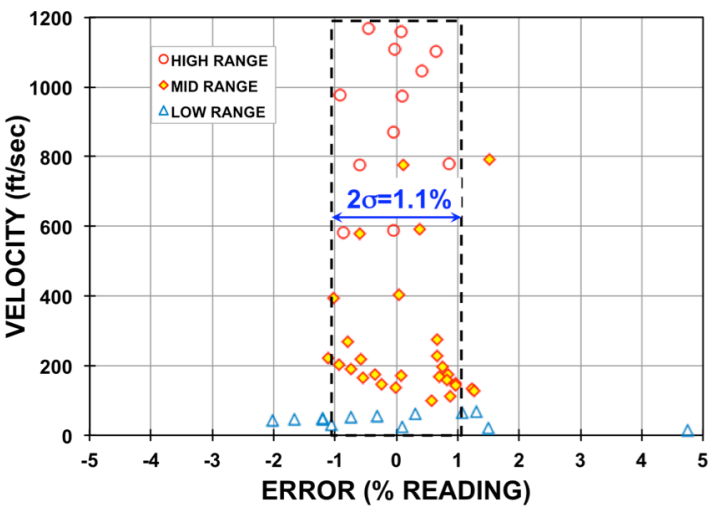

(b)

Figure 10. Hot-wire calibration and repeatability for a multi-range polynomial fit.

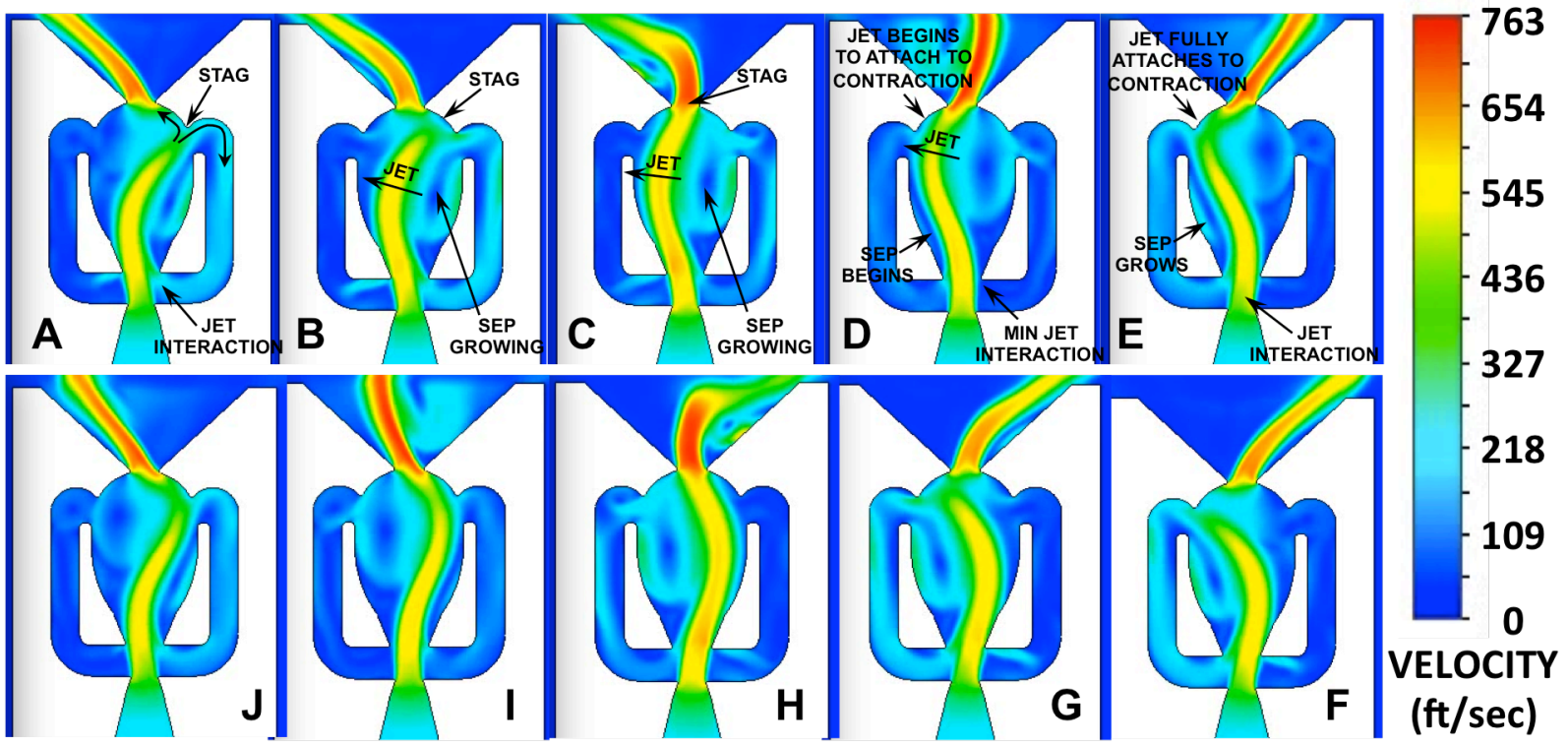

(a) Velocity profiles

Figure 11. CFD profiles for one sweep cycle that highlights variations of internal flow fields for actuator A, NPR=1.4. 

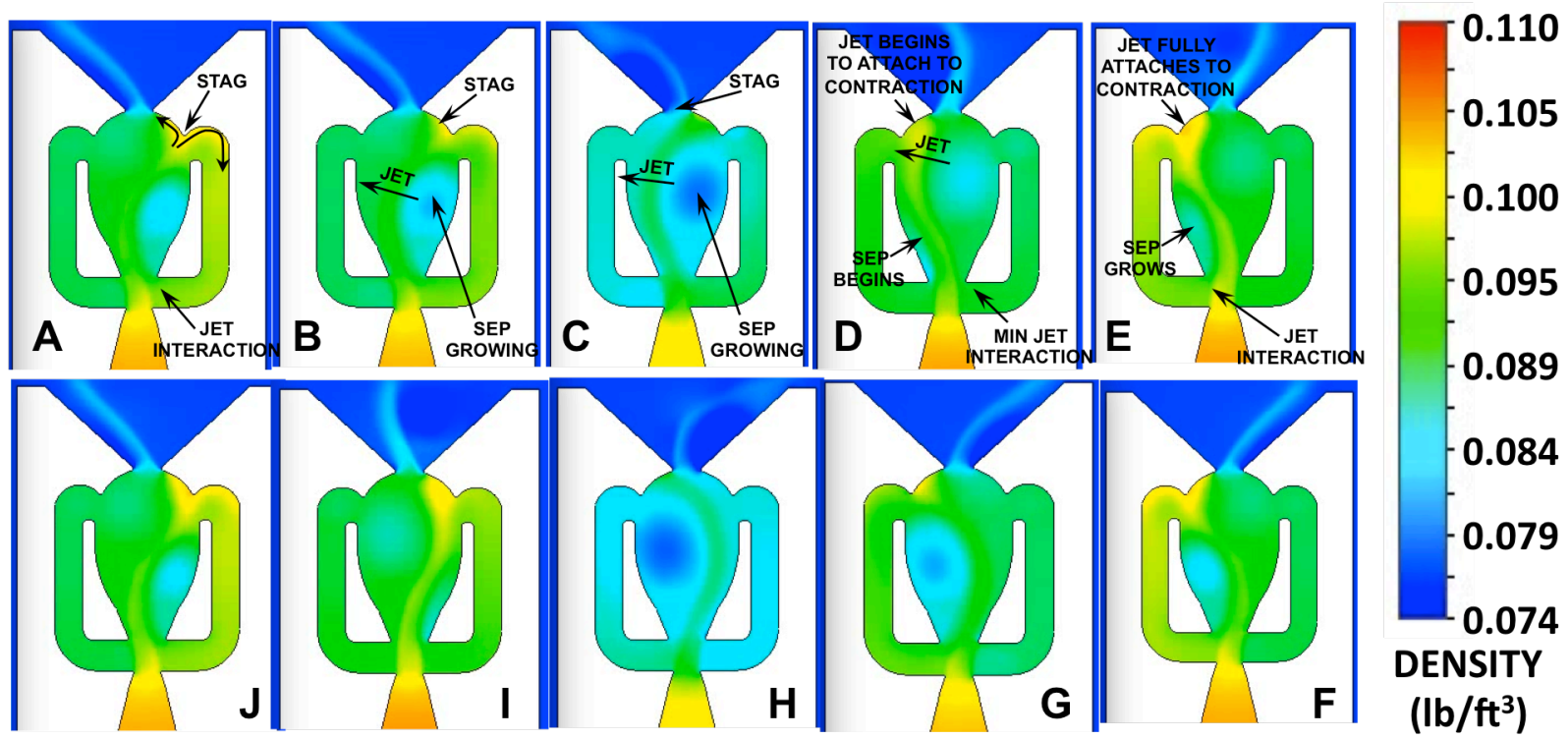

(b) Density profiles
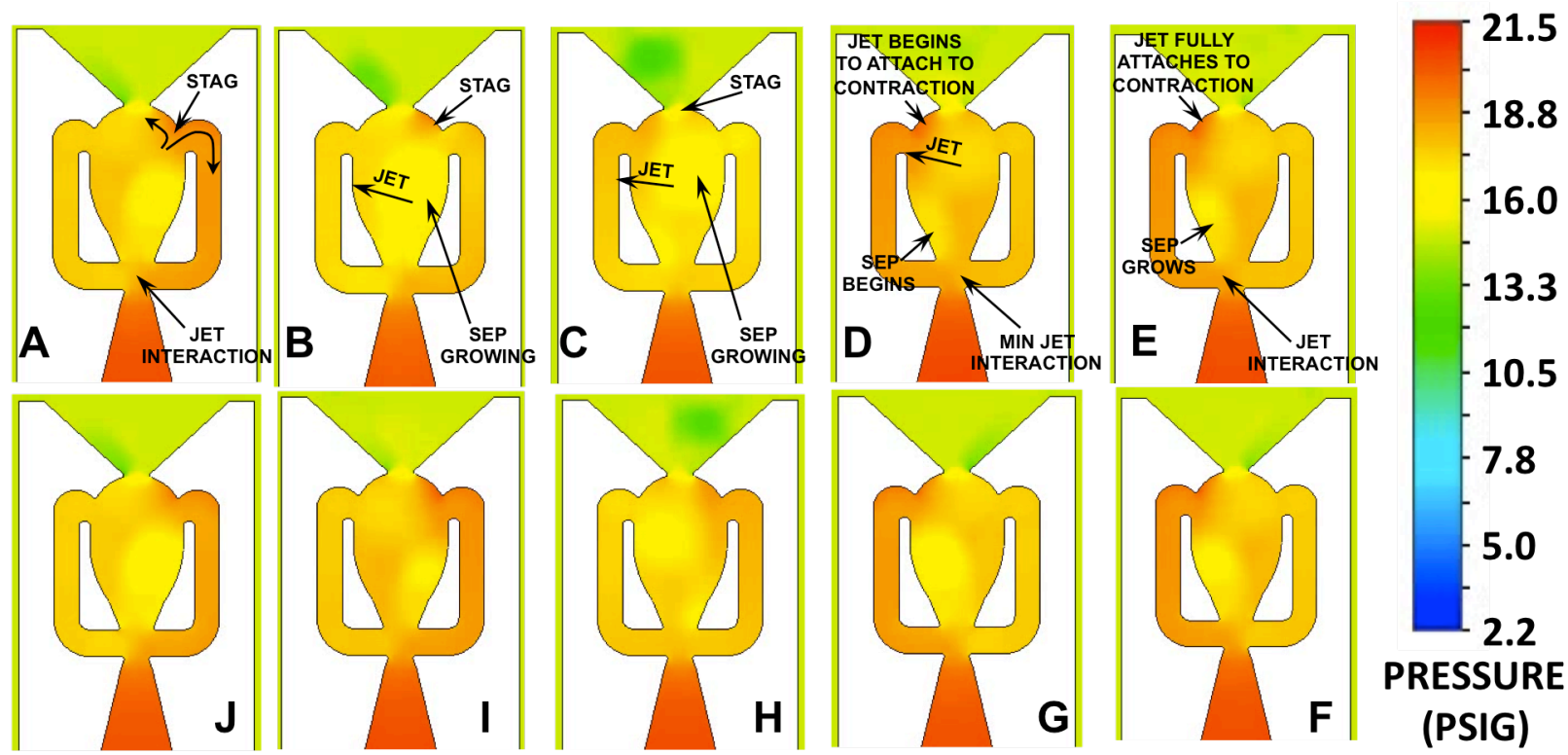

(c) Pressure profiles

Figure 11. CFD profiles for one sweep cycle that highlights variations of internal flow fields for actuator $A$, $\mathrm{NPR}=1.4$. 


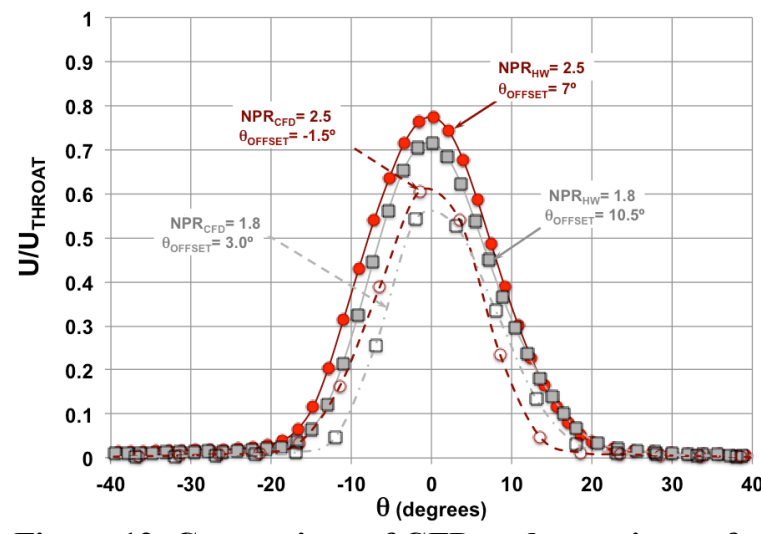

Figure 12. Comparison of CFD and experiment for a steady jet for actuator $\mathrm{A}, \mathrm{X} / \mathrm{Z}_{\mathrm{REF}}=\mathbf{0 . 2}$.

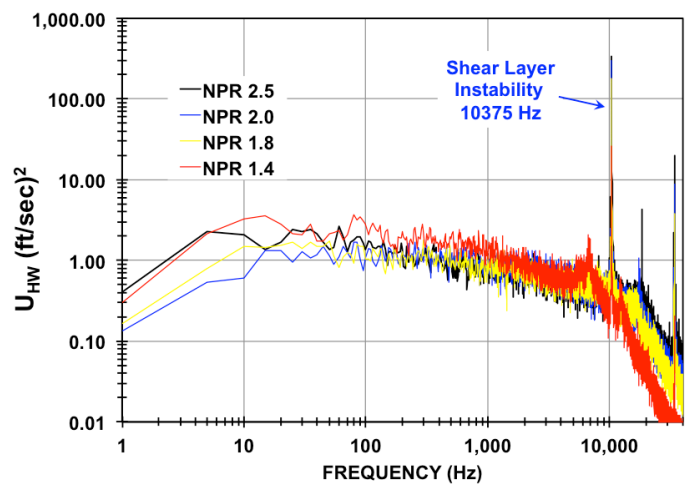

Figure 13. Hot wire spectra for a steady jet for actuator $\mathbf{A}$.

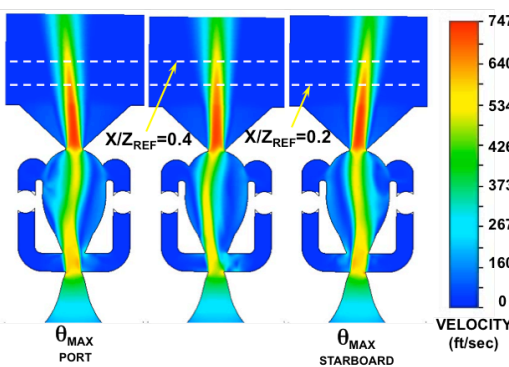

NPR=1.4

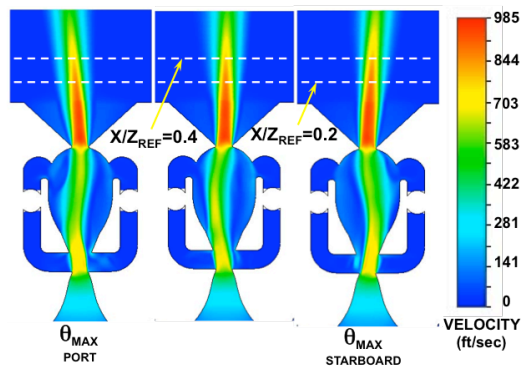

NPR=1.8

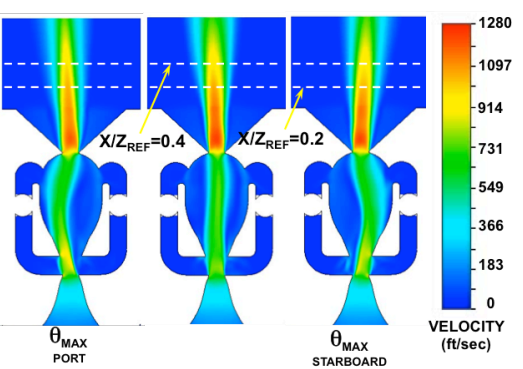

$\mathrm{NPR}=2.5$

Figure 14. CFD velocity profiles for actuator $A$ with feedback legs blocked.

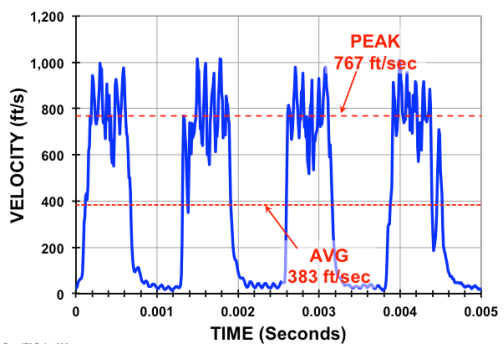

Frequency ${ }_{0}=785 \mathrm{~Hz}$

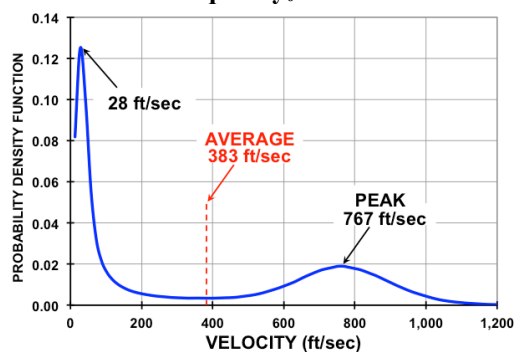

(a) $\theta=-24.74^{\circ}$

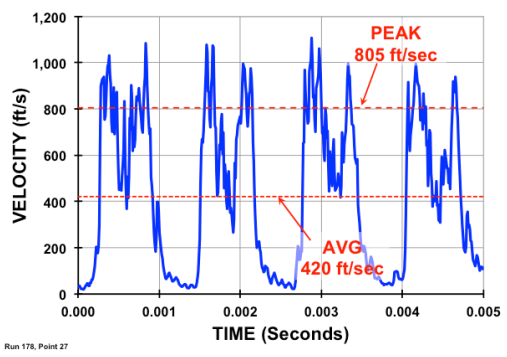

Frequency ${ }_{0}=785 \mathrm{~Hz}$ Frequency $_{1}=1570 \mathrm{~Hz}$

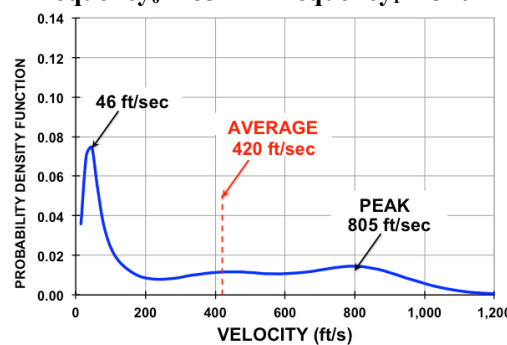

(b) $\theta=-12.97^{\circ}$
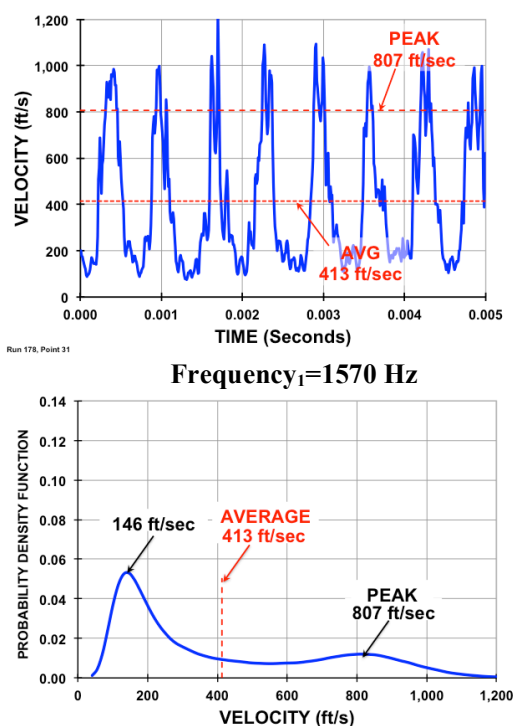

(c) $\theta=0.00^{\circ}$

Figure 15. Example of variation of amplitude response of actuator $F F$ at 3 spanwise positions, NPR=1.8, $\mathbf{X} / \mathbf{Z}_{\mathrm{REF}}=\mathbf{0 . 0 5}$. 


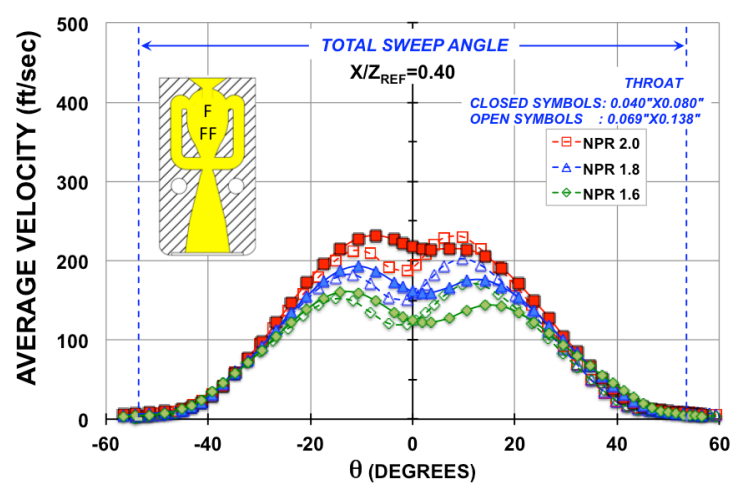

Figure 16. Comparison of two different scaled actuators $[F$ (closed symbols) and FF (open symbols)].

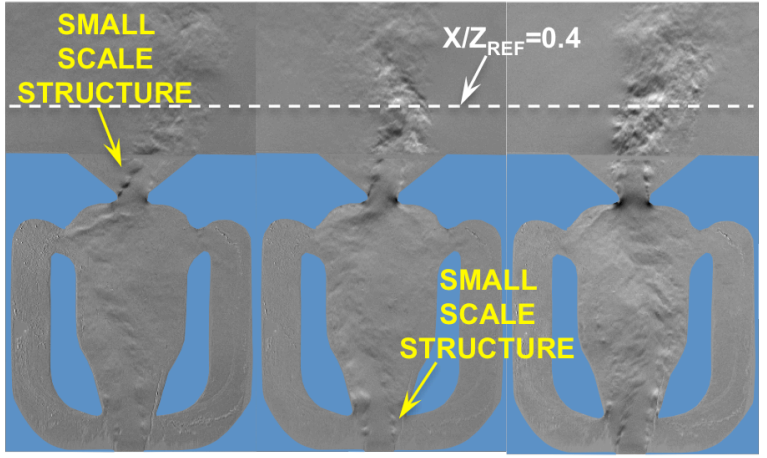

\section{$\mathrm{NPR}=1.4$ \\ $\mathrm{NPR}=1.8$ \\ $\mathrm{NPR}=\mathbf{2 . 0}$}

Figure 17. Schlieren images highlight coherent structure at inlet and throat shear layers (FF).
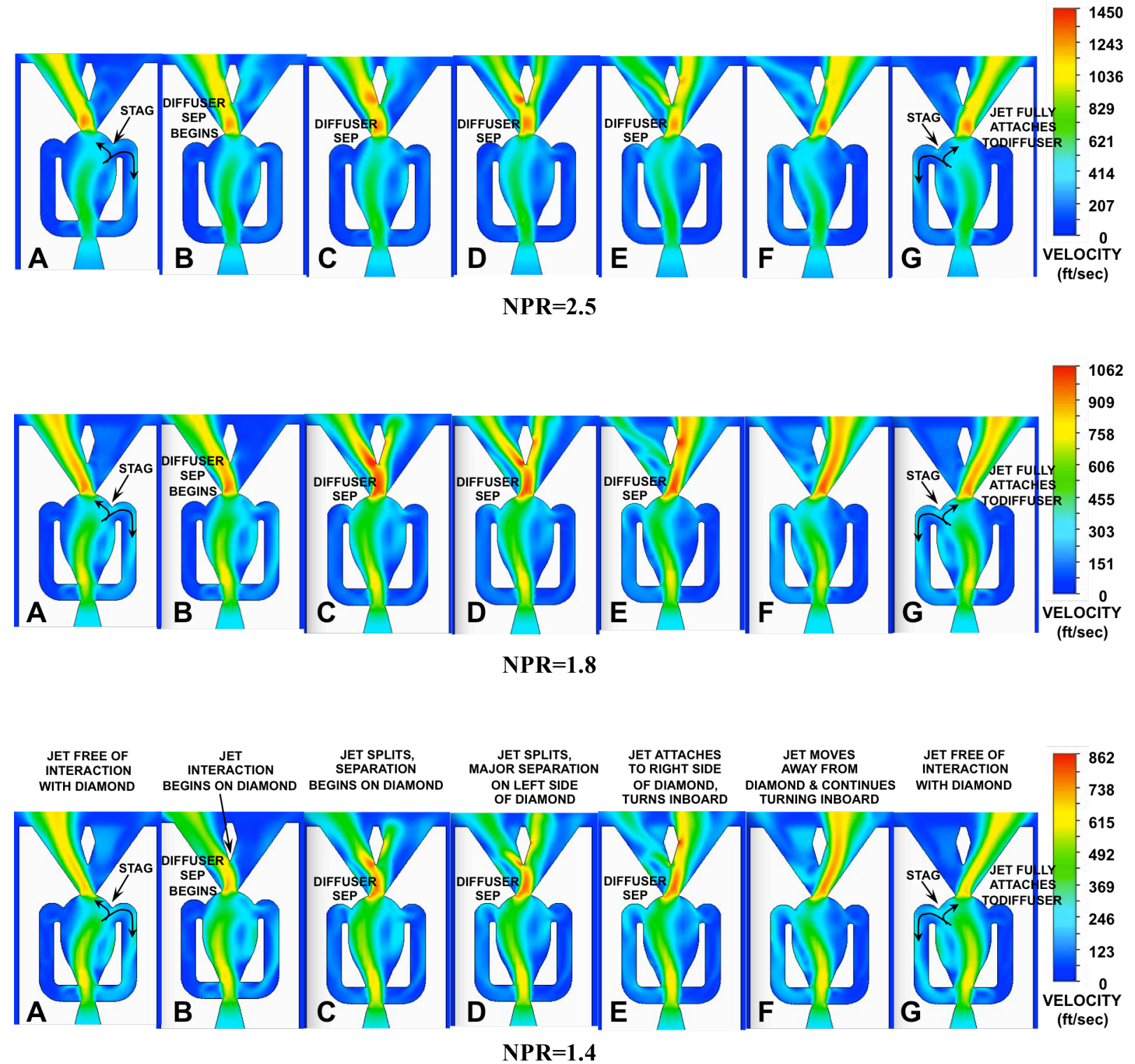

Figure 18. CFD half cycle of velocity profiles for actuator AA. 


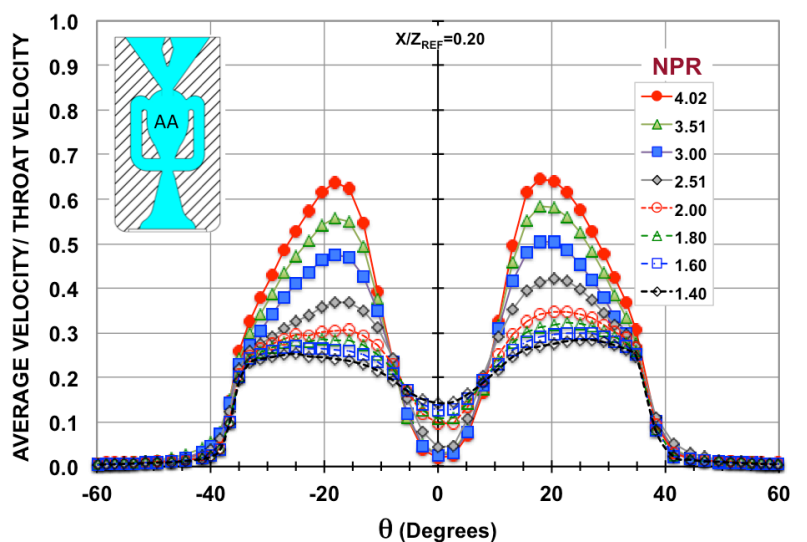

(a) THROAT: 0.080"x0.080" EXIT Y: 0.040" $Z_{\text {REF }}: 0.597$ "

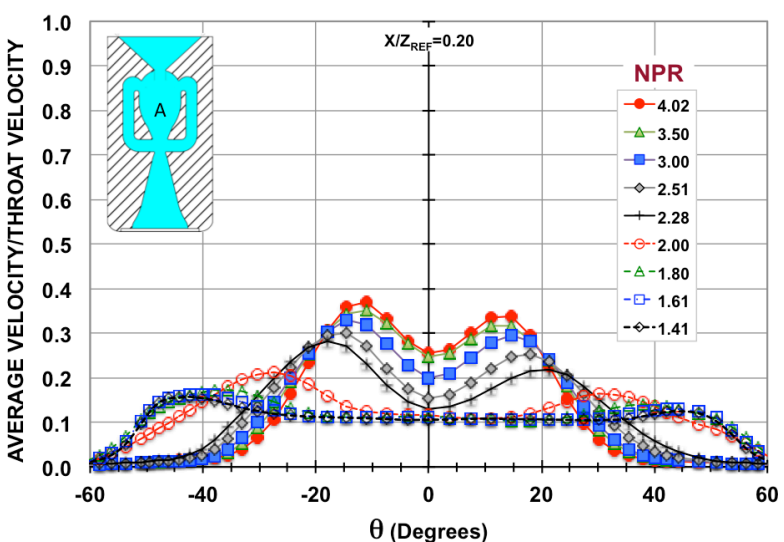

(b) THROAT: 0.040"x0.080" EXIT Y: 0.040" $Z_{\text {REF }}$ : 0.586" Figure 19. Comparison of performance for actuators $A A$ and $A$.

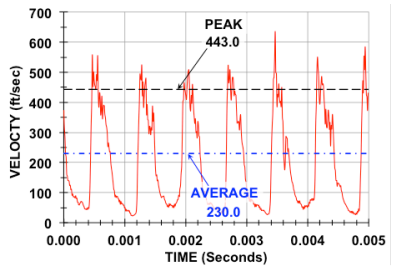

(a) $\mathrm{NPR}=1.6\left(\theta=-32.83^{\circ}\right)$

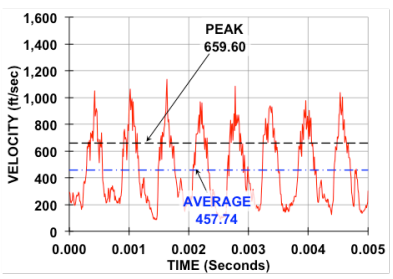

(e) $\mathrm{NPR}=4.0\left(\theta=-31.16^{\circ}\right)$

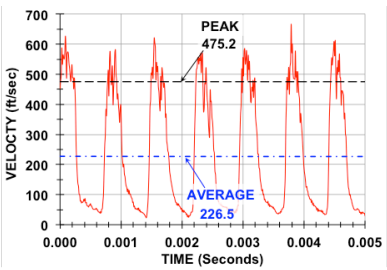

(b) $\mathrm{NPR}=1.6\left(\theta=-21.16^{\circ}\right)$

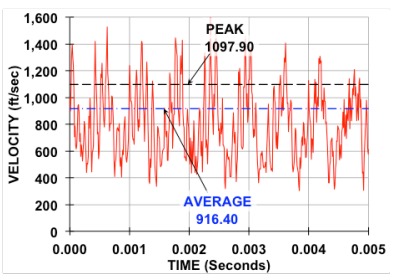

(f) $\mathrm{NPR}=4.0\left(\theta=-18.04^{\circ}\right)$

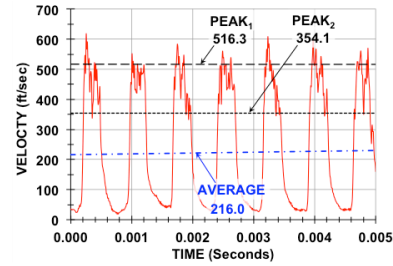

(c) $\mathrm{NPR}=1.6\left(\theta=-15.6^{\circ}\right)$

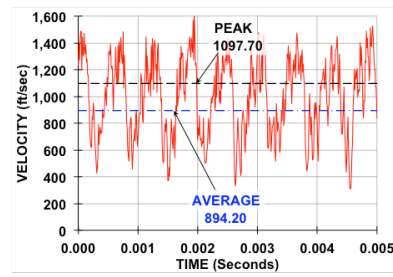

(g) $\mathrm{NPR}=4.0\left(\theta=-15.6^{\circ}\right)$

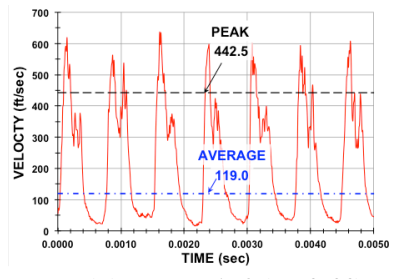

(d) $\mathrm{NPR}=1.6\left(\theta=0.0^{\circ}\right)$

Figure 20. Time histories for two NPRs of actuator $A A, X / Z_{R E F}=0.2$.

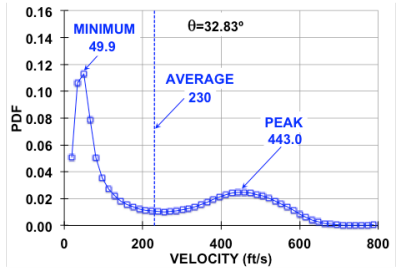

(a) $\operatorname{NPR}=1.6\left(\theta=-32.83^{\circ}\right)$

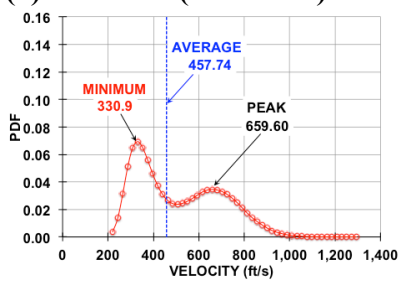

(e) $\mathrm{NPR}=4.0\left(\mathrm{q}=-31.16^{\circ}\right)$

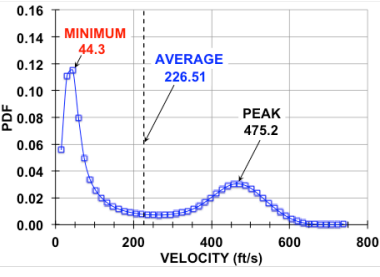

(b) $N P R=1.6\left(\theta=-21.16^{\circ}\right)$

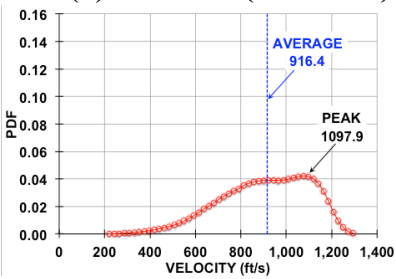

(f) $\mathrm{NPR}=4.0\left(\mathrm{q}=-18.04^{\circ}\right)$

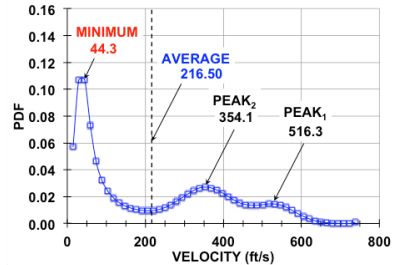

(c) $\mathrm{NPR}=1.6\left(\theta=-15.6^{\circ}\right)$

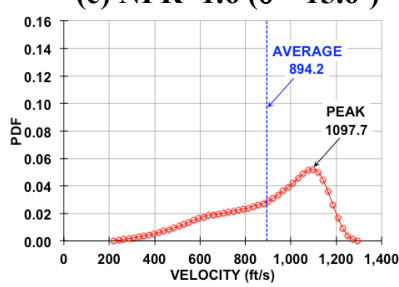

(g) $\mathrm{NPR}=4.0\left(\mathrm{q}=-15.6^{\circ}\right)$

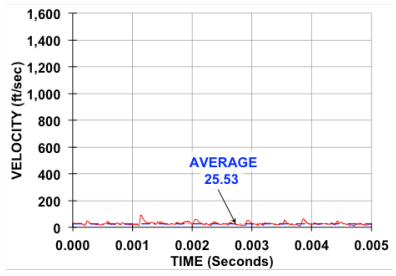

(h) $\mathrm{NPR}=4.0\left(\theta=0.0^{\circ}\right)$

Figure 21. Example of variation of velocity authority for actuator $A A$ at a $X / Z_{R E F}=0.2$. 


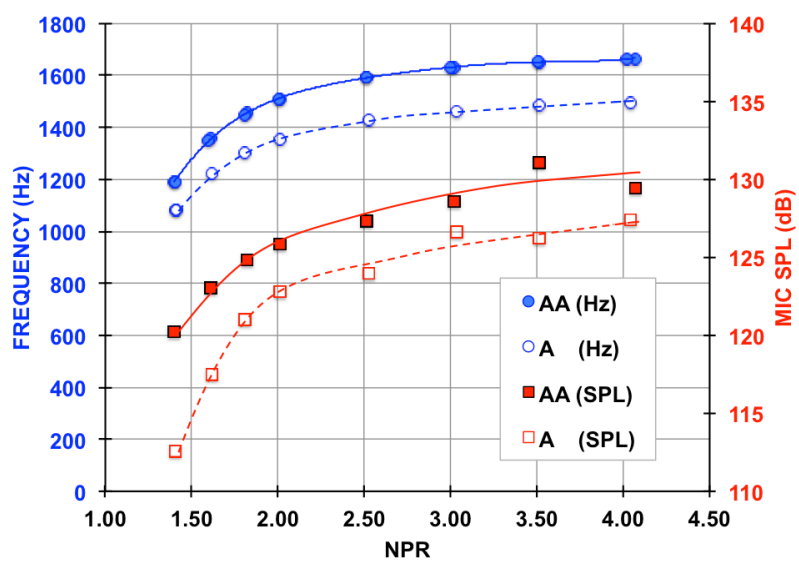

Figure 22. Sweeping jet peak frequency and corresponding SPL for actuators A and AA.

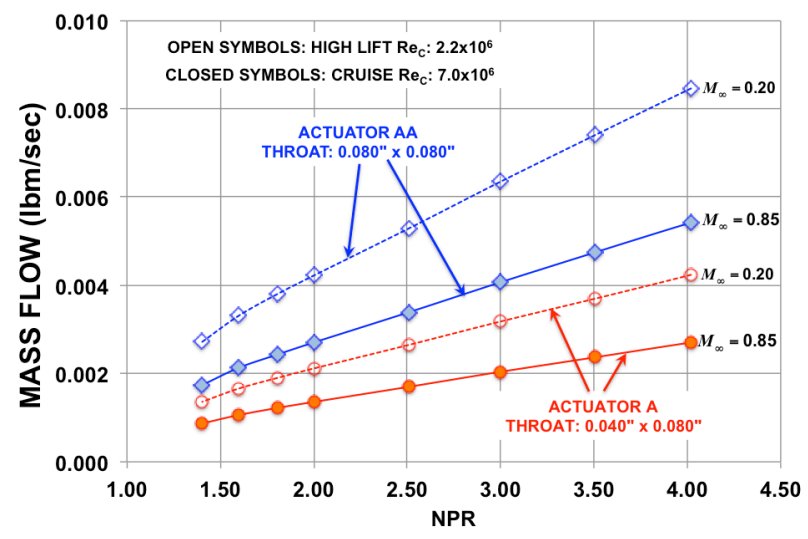

(a) $\mathrm{To}=70^{\circ} \mathrm{F}, \mathrm{T}_{\mathrm{JET}}=\mathbf{7 0}^{\circ} \mathrm{F}$

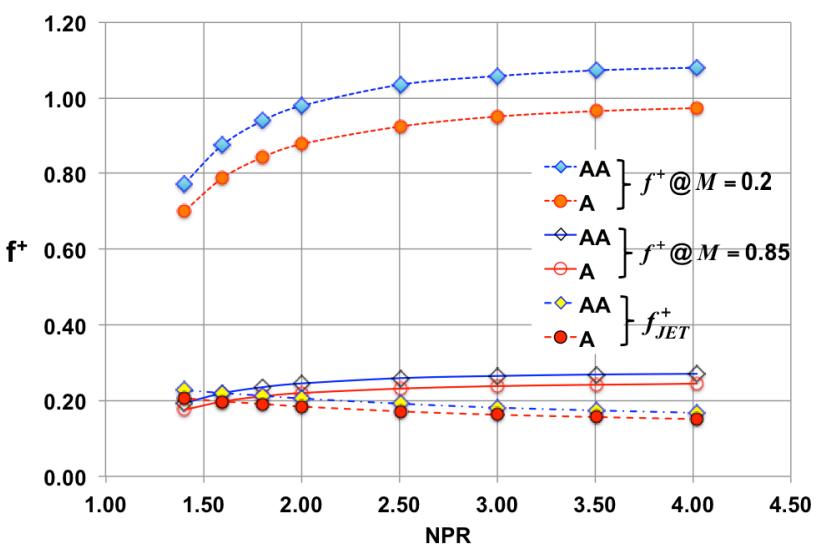

Figure 23. Nondimensional frequency for different throat sizes at ambient conditions, actuator $A$ and $A A$, $X_{\mathrm{TE}}=1.75$ " (FAST-MAC flap at wing tip).

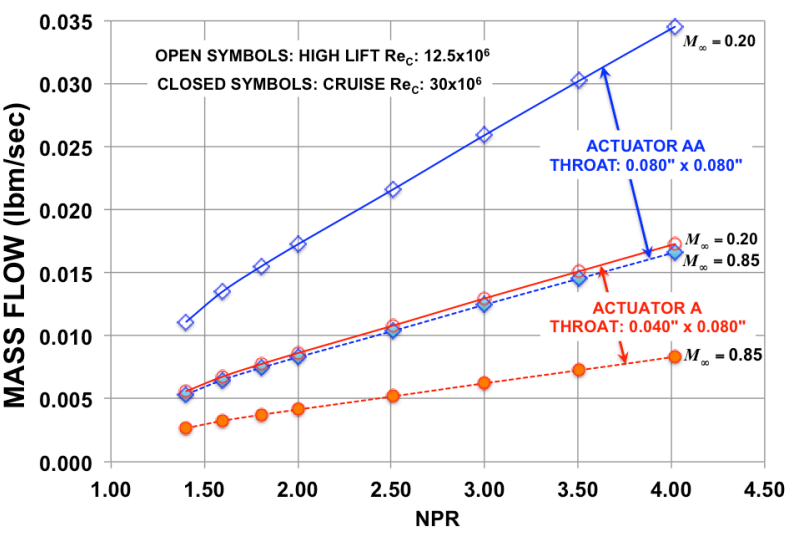

(b) $\mathrm{To}=-\mathbf{5 0}^{\circ}, \mathrm{T}_{\mathrm{JET}}=\mathbf{7 0}^{\circ} \mathrm{F}$

Figure 24. Ideal mass flow for actuator $A$ and AA.

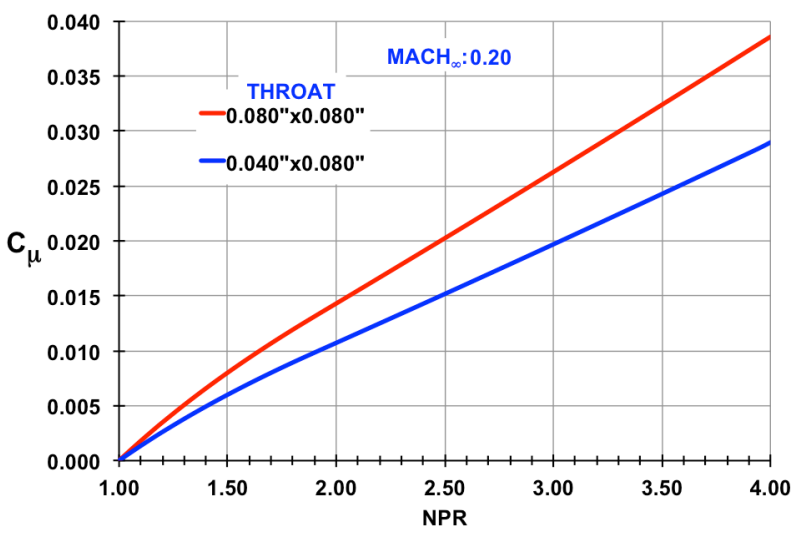

(a) FAST-MAC high-lift configuration

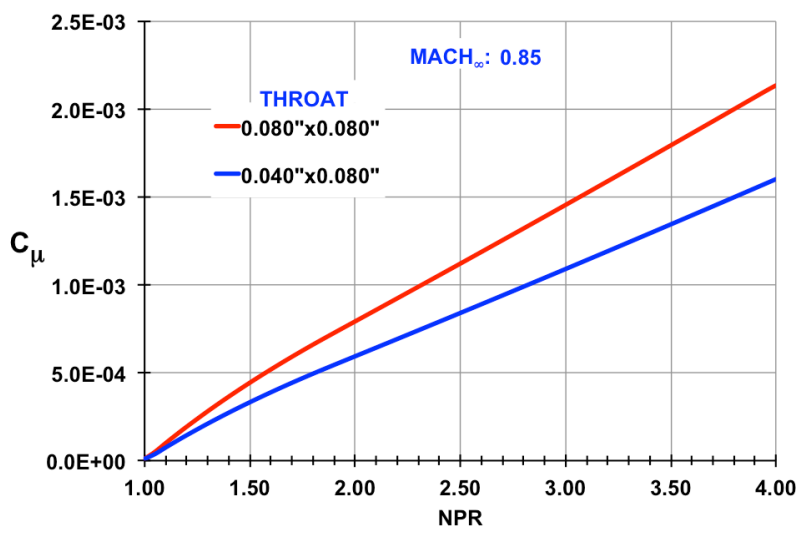

(b) FAST-MAC cruise configuration

Figure 25. Estimates for ideal momentum for actuator $A$ and $A A$ at two Mach numbers $(M=0.2$ for high-lift and $\mathrm{M}=\mathbf{0 . 8 5}$ for cruise).

18

American Institute of Aeronautics and Astronautics 


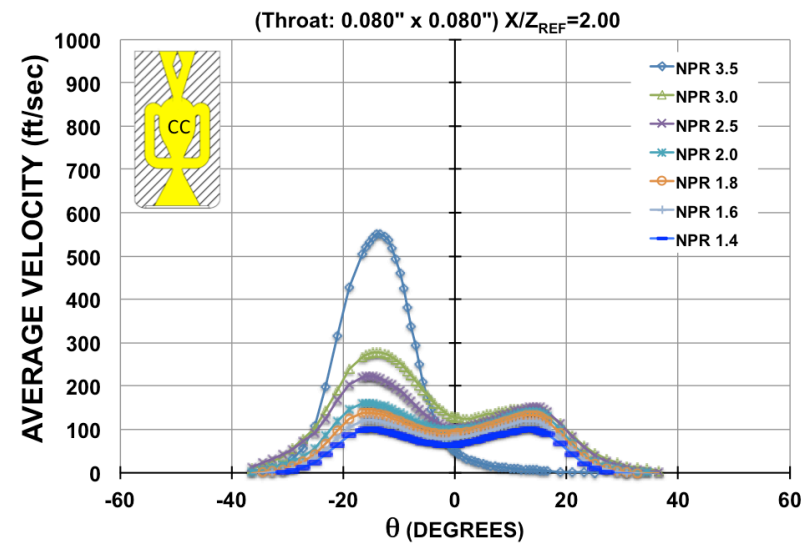

(a) Actuator $\mathrm{CC}$

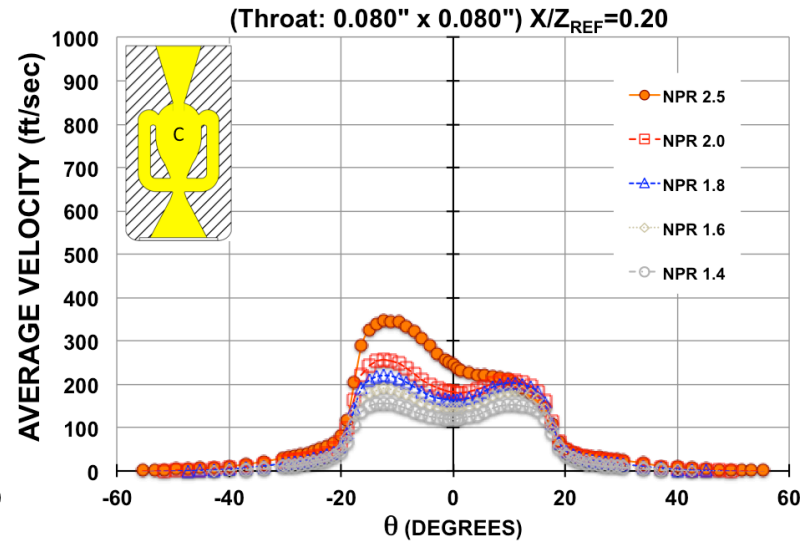

(b) Actuator $\mathrm{C}$

Figure 27. Comparison of actuator $\mathrm{CC}$ and $\mathrm{C}$.

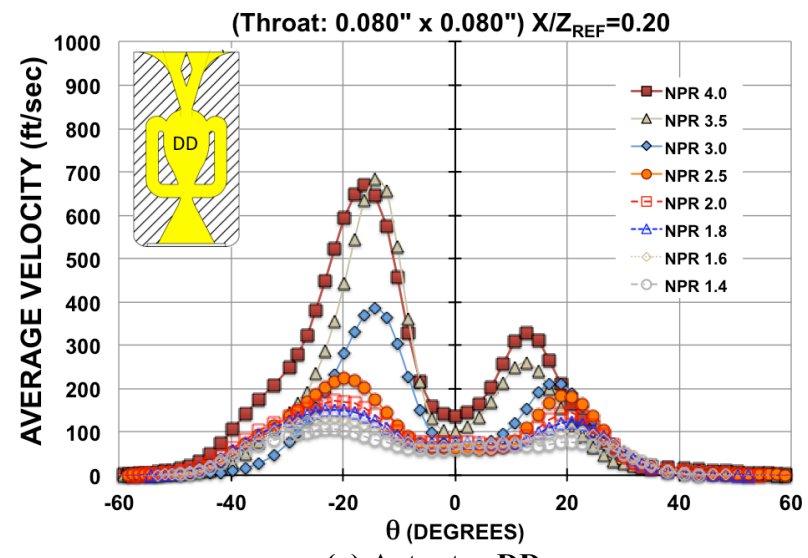

(a) Actuator DD

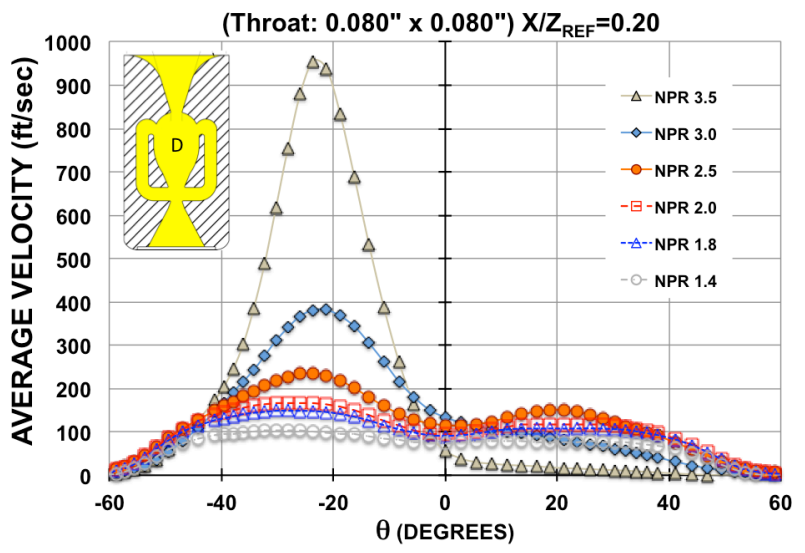

(b) Actuator D

Figure 28. Comparison of actuator DD and D.

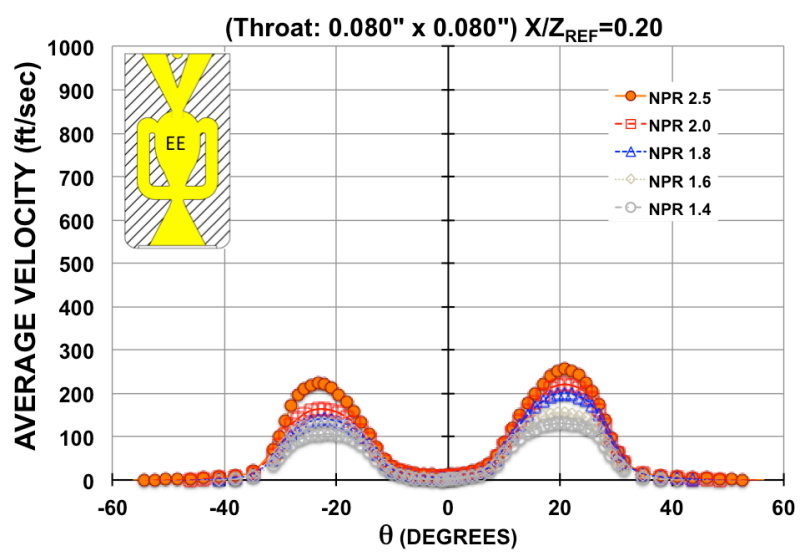

(a) Actuator EE

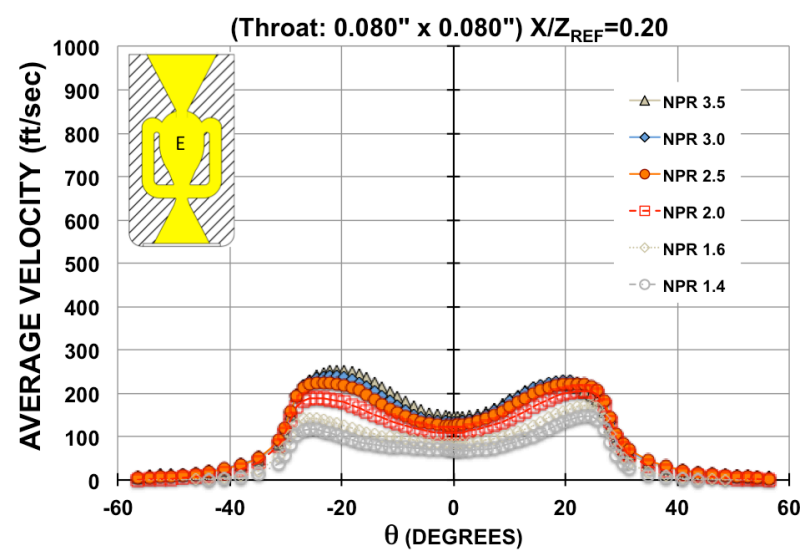

(b) Actuator $\mathbf{E}$

Figure 29. Comparison of actuator $E E$ and $E$. 


\section{References}

${ }^{1}$ Milholen II, W. E., Jones, G. S., Chan, D. T., Goodliff, S. G., "Enhancements to the FAST-MAC Circulation Control Model and Recent High-Reynolds Number Testing in the National Transonic Facility", AIAA Paper 2013-2794, June 2013.

${ }^{2}$ Chan, D. T., Milholen II, W. E., Jones, G. S., Goodliff, S. G., "Thrust Removal Methodology for the FAST-MAC Circulation Control Model Tested in the National Transonic Facility", AIAA Paper 2014-2402.

${ }^{3}$ Milholen II, W. E., Jones, G. S., Chan, D. T., Goodliff, S. G., "High-Reynolds Number Circulation Control Testing in the National Transonic Facility (Invited)", AIAA Paper 2012-0103, January 2012.

${ }^{4}$ Jones, G.S. (ed), Joslin, R.D. (ed), Procedings of the NASA/ONR 2004 Circulation Control Workshop, NASA CP2005-213509 (parts 1 and 2), June 2005.

5 Jones, G. S., Milholen II, W. E., Chan, D. T., Melton, L. P., Anders, S. G., Allan, B. G., Carter, M., Capone, F., Goodliff, S. L., "Development of the Circulation Control Flow Scheme used in the NTF Semi-Span Model Support System," AIAA Paper 2013-3048, January 2013.

${ }^{6}$ Iberall, A.S., "Attenuation of Oscillatory Pressures in Instrument Lines", Research Paper RP2115, National Bureau of Standards, 1950.

${ }^{7}$ Belsterling, C.A., "Fluidic Systems Design", John Wiley and Sons, 1971.

${ }^{8}$ Gad-el-Hak, M., "Flow Control - Passive, Active, and Reactive Flow Management", Cambridge University Press, 2000.

9 Joslin, R.D. (ed.), Miller, D.N. (ed.), "Fundamentals and Application of Modern Flow Control," Volume 231 Progress in Astornautics and Aeronautics, 2009.

${ }^{10}$ Gregory, J.W., Sullivan, J.P., Raman, G, and Raghu, S., “Characterization of a Micro-Fluidic Oscillator for Flow Control, AIAA Paper 2004-2692, 2004

${ }^{11}$ Andino, M.Y., Lin, J.C., Washburn, A.E., Whalen, E.A., Graff, E.C., Wygnanski, I.J., "Flow Separation Control on a Full-Scale Vertical Tail Model using Sweeping Jet Actuators", AIAA Paper 2015-0785, January 2015.

${ }^{12}$ Melton, Latunia, P., "Active Flow Separation Control on a NACA 0015 Wing using Fluidic Actuators", AIAA paper 2014-2364, June 2014.

${ }^{13}$ Melton, L., P., Hannon, J., Yao C.S., Harris, J., "Active Flow Control at Low Reynolds Numbers on a NACA 0015 Airfoil”, AIAA Paper 2008-6407, August 2008.

${ }^{14}$ Seele, R., Graff, E., Lin, J., Wygnanski, I., "Performance Enhancement of a Vertical Tail Model with Sweeping Jet Actuators", AIAA Paper 2013-0411, January 2013.

${ }^{15}$ Greenblatt, D. and Wygnanski, I., "The Control of Flow Separation by Periodic Excitation," Progress in Aerospace Sciences, Vol. 36, 2004, pp. 487-545.

${ }^{16}$ Koklu, M. Melton, L.P., "Sweeping Jet Actuator in a Quiescent Environment", AIAA Paper 2014-2477, June 2013.

${ }^{17}$ Koklu, M., "The Effects of Sweeping Jet Actuator Parameters on Flow Separation Control”, AIAA Paper 20152485, June 2015

${ }^{18}$ Woszidlo, R., Wygnanski, I., "Parameters Governing Separation Control with Sweeping Jet Actuators", AIAA Paper 2011-3172, June 2011.

${ }^{19}$ Pack, L.G., Seifert, A., "Periodic Excitation for Jet Vectoring and Enhanced Spreading," AIAA Paper 99-0672, January 1999.

${ }^{20}$ Woszidlo, R., Nawroth, H, Raghu, S., and Wygnanski, I., "Parametric Study of Sweeping Jet Actuators for Separation Control", AIAA paper 2010-4247, June 2010.

${ }^{21}$ Seifert, A., Greenblatt, D. and Wygnanski, I., "Active separation control: an overview of Reynolds and Mach numbers effects", Aerospace Science and Technology 8 (2004) 569-582

${ }^{22}$ Greenblatt, D. and Washburn, A., "Influence of Finite Span and Sweep on Active Flow Control Efficacy," AIAA Journal,Vol. 46, No. 7, 2008, pp. 1675-1694.

${ }^{23}$ Seifert, A, Tilmann, C.P., "Fixed Wing Airfoil Applications," Chapter 8, Fundamental and Application of Modern Flow Control, Volume 231 Progress in Astornautics and Aeronautics, 2009.

${ }^{24}$ Bobusch, B.C., Woszidlo, R., Kruuger, O., and Paschereit, C.O., "Numerical Investigations on Geometric Parameters Affecting the Oscillation Properties of a Fluidic Oscillator," AIAA 2013-2709, June 2103.

${ }^{25}$ Vatsa, V. N., Koklu, M., Wygnanski, I. J., and Fares, E., "Numerical Simulation of Fluidic Actuators for Flow Control Applications," AIAA Paper 2012-3239, 2012.

${ }^{26}$ Ivanov, A.V., Trebunskikh, T.V., Platonovich, V.V., "Validation Methodology For Modern CAD-Embedded CFD Code: From Fundamental Tests To Industrial Benchmarks", NAFEMS World Congress 2013. 
${ }^{27}$ Peters, C.J., Miles, R.B., Burns, R.A., Danehy, P.M., Bathel, B.F., and Jones, G.S., "Femtosecond Laser Tagging Characterization of a Sweeping Jet Actuator Operating in the Compressible Regime", AIAA Paper to be presented at the $32^{\text {nd }}$ Aerodynamic Measurement Technology and Ground Testing Conference, Washington D.C., June 2016. 